\title{
Camphor Activates and Strongly Desensitizes the Transient Receptor Potential Vanilloid Subtype 1 Channel in a Vanilloid-Independent Mechanism
}

\author{
Haoxing Xu, ${ }^{\star}$ Nathaniel T. Blair, ${ }^{*}$ and David E. Clapham \\ Howard Hughes Medical Institute, Children's Hospital, Harvard Medical School, Boston, Massachusetts 02115
}

\begin{abstract}
Camphor is a naturally occurring compound that is used as a major active ingredient of balms and liniments supplied as topical analgesics. Despite its long history of common medical use, the underlying molecular mechanism of camphor action is not understood. Capsaicin and menthol, two other topically applied agents widely used for similar purposes, are known to excite and desensitize sensory nerves by acting on two members of transient receptor potential (TRP) channel superfamily: heat-sensitive TRP vanilloid subtype 1 (TRPV1) and cold-sensitive TRP channel M8, respectively. Camphor has recently been shown to activate TRPV3, and here we show that camphor also activates heterologously expressed TRPV1, requiring higher concentrations than capsaicin. Activation was enhanced by phospholipase C-coupled receptor stimulation mimicking inflamed conditions. Similar camphor-activated TRPV1-like currents were observed in isolated rat DRG neurons and were strongly potentiated after activation of protein kinase $\mathrm{C}$ with phorbol-12-myristate-13acetate. Camphor activation of rat TRPV1 was mediated by distinct channel regions from capsaicin, as indicated by camphor activation in the presence of the competitive inhibitor capsazepine and in a capsaicin-insensitive point mutant. Camphor did not activate the capsaicin-insensitive chicken TRPV1. TRPV1 desensitization is believed to contribute to the analgesic actions of capsaicin. We found that, although camphor activates TRPV1 less effectively, camphor application desensitized TRPV1 more rapidly and completely than capsaicin. Conversely, TRPV3 current sensitized after repeated camphor applications, which is inconsistent with the analgesic role of camphor. We also found that camphor inhibited several other related TRP channels, including ankyrin-repeat TRP 1 (TRPA1). The camphor-induced desensitization of TRPV1 and block of TRPA1 may underlie the analgesic effects of camphor.
\end{abstract}

Key words: camphor; capsaicin; TRPV1; dorsal root ganglion; DRG; nociceptor; transient receptor potential; topical analgesic

\section{Introduction}

Camphor, capsaicin (the pungent ingredient in chili peppers), and menthol are plant-derived natural products well known for their sensory effects. Camphor is isolated from the wood of the camphor laurel tree (Cinnamomum camphora) and is used as a nasal decongestant and cough suppressant (Burrow et al., 1983). Camphor is also commonly applied to the skin for antipruritic, analgesic, and counterirritant properties (Burkhart and Burkhart, 2003). Despite the long history and widespread use, the molecular and cellular targets of camphor are unknown. In contrast, capsaicin and menthol are known to excite and subsequently desensitize sensory neurons by acting on two members of

Received June 22, 2005; revised Aug. 12, 2005; accepted Aug. 15, 2005.

This work was supported by Howard Hughes Medical Institute and National Institutes of Health postdoctoral fellowship T32 NS07484-04 (N.T.B.). We thank Dr. David Julius for rat TRPV1, TRPV2, TRPM8, TRPA1, and chicken TRPV1 constructs. We also thank Dr. Sven-Eric Jordt for Y511A rat TRPV1 and V2-4C (crCTRPV1) chimeric constructs, Dr. Michael Caterina for the mouse TRPV3 construct, Drs. Markus Delling and Dejian Ren for mouse TRPV3 and TRPV4 constructs, respectively, and Dr. Vassilios Bezzerides for mouse TRPC5-GFP constructs. We thank Drs. Susan Cibulsky, Sven-Eric Jordt, Ru-rong Ji, Lixia Yue, and members of the Clapham laboratory for discussion and helpful comments. ${ }^{*}$ H.X. and N.T.B. contributed equally to this work.

Correspondence should be addressed to David E. Clapham, Howard Hughes Medical Institute, Children's Hospital, Harvard Medical School, Enders 1309, 320 Longwood Avenue, Boston, MA 02115. E-mail: dclapham@ enders.tch.harvard.edu.

DOI:10.1523/JNEUROSCI.2574-05.2005

Copyright $\odot 2005$ Society for Neuroscience $\quad$ 0270-6474/05/258924-14\$15.00/0 transient receptor potential (TRP) channel superfamily, TRP vanilloid subtype 1 (TRPV1) and TRP channel M8 (TRPM8), respectively (Caterina et al., 1997; McKemy et al., 2002; Peier et al., 2002a).

Multiple mammalian TRP genes have been cloned and classified into six subfamilies that are widely expressed and play diverse roles in thermosensation, mechanosensation, pheromone sensing, and gustation (Clapham, 2003; Montell, 2005). Several members of the TRPV subfamily (V1-V4) as well as TRPM8 and ankyrin-repeat TRP 1 (TRPA1) are expressed in sensory cells, particularly in nociceptive sensory neurons, and are crucial in the detection of temperature (thermoTRPs) (Jordt et al., 2003; Patapoutian et al., 2003), although the cold temperature activation of TRPA1 is unclear (Story et al., 2003; Bandell et al., 2004; Jordt et al., 2004; Nagata et al., 2005). These thermoTRPs detect a wide range of temperatures spanning from noxious cold and heat as well as cool and warmth (for review, see Patapoutian et al., 2003; Wang and Woolf, 2005). Interestingly, all thermoTRP channels are apparently also chemosensitive, potentially enabling these channels to detect multiple sensory modalities. For example, TRPV1 is stimulated by capsaicin and protons, TRPM8 is sensitive to menthol, and TRPAl can be activated by mustard and cinnamon oil. For TRPV1 and TRPM8, the psychophysical sensations elicited by capsaicin and menthol match their respective thermal detection properties, "hot" and "cool." 
Chemosensitive and thermosensitive TRP channels often exhibit desensitization after prolonged or repeated stimulations to adapt to changing stimulus levels. TRPV1 exhibits two types of desensitization: acute desensitization, which is the diminished response during a constant agonist application, and tachyphylaxis, which is the reduction of the response to multiple stimulations (Koplas et al., 1997; Bhave et al., 2002). The desensitization of TRPV1 likely contributes to the analgesic effects of capsaicin (Jancso et al., 1967; Szolcsanyi, 2004).

It was recently reported that camphor specifically activated TRPV3, and camphor-induced currents were recorded from keratinocytes but not sensory neurons (Moqrich et al., 2005). Camphor is known to produce a warm sensation (Green, 1990), consistent with the thermal activation range of TRPV3. However, repeated camphor applications sensitized TRPV3, apparently contradicting its analgesic role (Peier et al., 2002b; Moqrich et al., 2005). We found that camphor also activates TRPV1 and a TRPV1-like current in dorsal root ganglion (DRG) neurons but inhibits the TRPA1 channel, which is expressed in most nociceptive DRG neurons (Nagata et al., 2005). Camphor-activated TRPV1 currents underwent significant desensitization and tachyphylaxis, which, together with inhibition of TRPA1, might generate the antipruritic, analgesic, and counterirritant properties of camphor.

\section{Materials and Methods}

Heterologous expression of TRP channels in human embryonic kidney cells. Rat TRPV1 (rTRPV1), rat TRPV2 (rTRPV2), mouse TRPV3 (mTRPV3), and mouse TRP channel 5 (mTRPC5) were cloned into enhanced green fluorescence protein (EGFP; BD Biosciences, Mountain View, CA) vectors to generate $\mathrm{C}$-terminal fusion proteins. Mouse TRPV4 was subcloned into an EGFP-containing vector (pTracer-CMV2; Invitrogen, Carlsbad, CA), and other constructs were cloned into pcDNA3 and cotransfected with pTracer-CMV2 for expression. Human embryonic kidney 293T (HEK293T) cells and HEK cells stably expressing the muscarinic M1 receptor (HM1) were transfected using Lipofectamine 2000 (Invitrogen) transfection reagent $(6-8 \mathrm{~h})$. Transfected cells were cultured at $37^{\circ} \mathrm{C}$, plated onto glass coverslips, and used for electrophysiological recordings after $24 \mathrm{~h}$. Transfected cells were identified by GFP fluorescence.

Preparation of DRG neurons. DRGs from all spinal levels were removed from postnatal day 12 (P12) to P18 Sprague Dawley rats, trimmed of their roots, and treated for $20 \mathrm{~min}$ at $37^{\circ} \mathrm{C}$ in $20 \mathrm{U} / \mathrm{ml}$ of papain (Worthington Biochemical, Lakewood, $\mathrm{NJ}$ ) with $5 \mathrm{~mm}$ cysteine in a $\mathrm{Ca}^{2+}$, $\mathrm{Mg}^{2+}$-free (CMF) Hank's solution containing the following (in $\mathrm{mM}$ ): $136.9 \mathrm{NaCl}, 5.4 \mathrm{KCl}, 0.34 \mathrm{Na}_{2} \mathrm{HPO} 4,0.44 \mathrm{KH}_{2} \mathrm{PO}_{4}, 5.55$ glucose, 5 HEPES, $0.005 \%$ phenol red, $\mathrm{pH} 7.4$. Ganglia were then transferred to the CMF Hank's solution with $3 \mathrm{mg} / \mathrm{ml}$ collagenase (type I; Worthington) and $4 \mathrm{mg} / \mathrm{ml}$ dispase (neutral type II; Roche Applied Science, Indianapolis, IN) and incubated at $37^{\circ} \mathrm{C}$ for $20 \mathrm{~min}$. Individual neurons were dispersed by trituration through a fire-polished glass Pasteur pipette in Leibovitz's L-15 medium (Invitrogen); supplemented with 10\% fetal calf serum, $100 \mathrm{U} / \mathrm{ml}$ penicillin, $100 \mu \mathrm{g} / \mathrm{ml}$ streptomycin, $5 \mathrm{~mm}$ HEPES, and $100 \mathrm{ng} / \mathrm{ml}$ nerve growth factor (7S subunit; Invitrogen); and plated on poly-D-lysine $(200 \mu \mathrm{g} / \mathrm{ml})$-coated glass coverslips. DRG neurons were kept at $33^{\circ} \mathrm{C}$ for $3-4 \mathrm{~h}$, moved to $4^{\circ} \mathrm{C}$ to reduce neurite outgrowth, and used within $36 \mathrm{~h}$.

Electrophysiology. For most recordings from EGFP-positive HEK cells, the pipette solution contained the following (in $\mathrm{mm}$ ): $147 \mathrm{Cs}, 120$ methane-sulfonate, $8 \mathrm{NaCl}, 10$ EGTA, $2 \mathrm{Mg}$-ATP, and 20 HEPES, pH 7.4. The pipette solution for mTRPC5-mediated currents (see Fig. 3G, $H$ ) was the Cs-aspartate-based internal solution used for DRG neurons (see below). For the receptor-stimulation experiments shown in Figure 7, to preserve the intracellular signaling, the pipette solution contained the following (in mM): $147 \mathrm{Cs}, 120$ methane-sulfonate, $8 \mathrm{NaCl}, 4.1 \mathrm{CaCl}_{2}, 10$ EGTA, $2 \mathrm{Mg}$-ATP, $0.3 \mathrm{Na}_{2}$-GTP, and 20 HEPES, pH $7.2\left(\right.$ free $\left[\mathrm{Ca}^{2+}\right]_{\mathrm{i}}$, $\sim 120$ nM using MaxChelator; available at http://www.stanford.edu/ $\sim$ cpatton/webmaxc/webmaxcS.htm). Standard extracellular solution (Tyrode's solution) contained the following (in mM): $150 \mathrm{NaCl}, 5 \mathrm{KCl}, 2$ $\mathrm{CaCl}_{2}, 1 \mathrm{MgCl}_{2}, 10$ glucose, and 20 HEPES, pH 7.4. Low extracellular $\mathrm{Ca}^{2+}$ solution, used to minimize TRPV1 desensitization in Figure $6 \mathrm{H}$, contained $1 \mathrm{~mm}$ EGTA (replacing $2 \mathrm{~mm} \mathrm{CaCl}$ ). In experiments designed to examine proton activation of TRPV1, we used a low $\mathrm{pH}$ solution that contained the following (in $\mathrm{mm}$ ): $150 \mathrm{Na}$-gluconate, $5 \mathrm{KCl}, 2 \mathrm{CaCl}_{2}, 1$ $\mathrm{MgCl}_{2}, 10$ glucose, 10 HEPES, 10 MES, $\mathrm{pH}$ 4.2. This low $\mathrm{Cl}^{-}$solution significantly reduced the amplitude of endogenous proton-activated $\mathrm{Cl}^{-}$ currents present in HEK cells (Xu et al., 2004).

Solutions used to record camphor- and capsaicin-activated currents in DRG neurons were designed to minimize the contributions of large voltage-gated currents (Blair and Bean, 2002). The internal solution contained the following (in mM): 150 Cs-aspartate, $0.36 \mathrm{CaCl}_{2}, 1$ EGTA, $2 \mathrm{MgCl}_{2}, 10$ HEPES, $4 \mathrm{MgATP}$, and $0.3 \mathrm{Na}-\mathrm{GTP}, \mathrm{pH}$ 7.2. The free intracellular $\left[\mathrm{Ca}^{2+}\right]_{\mathrm{i}}$ of this solution was estimated to be $\sim 100 \mathrm{nM}$ (MaxChelator). Two external solutions were used: one was a "low-K Tyrode's solution" containing the following (in mM): $150 \mathrm{NaCl}, 4 \mathrm{CsCl}, 0$ or $1 \mathrm{KCl}, 2 \mathrm{CaCl}_{2}, 1 \mathrm{MgCl}_{2}, 0.03 \mathrm{CdCl}_{2}, 5$ tetraethylammonium (TEA) $\mathrm{Cl}$, 10 glucose, 10 HEPES, and $1 \mu \mathrm{M}$ tetrodotoxin (TTX), pH 7.4. Seals in this solution at times became unstable, and in some experiments requiring multiple solution applications, we used a "Tyrode's solution with blocker," which contained the following: $150 \mathrm{~mm} \mathrm{NaCl}, 4 \mathrm{~mm} \mathrm{KCl}, 2 \mathrm{~mm}$ $\mathrm{CaCl}_{2}, 1 \mathrm{~mm} \mathrm{MgCl}_{2}, 10 \mathrm{~mm}$ glucose, $10 \mathrm{~mm}$ HEPES, $1 \mu \mathrm{M}$ TTX, $2 \mu \mathrm{M}$ nimodipine, $1 \mu \mathrm{M} \omega$-conotoxin GVIA, and, in most cases, $125 \mathrm{~nm}$ $\omega$-AgaIVA. Basal ramp currents (inward and outward) were slightly smaller in the low-K Tyrode's solution yet remained small in amplitude in Tyrode's solution with blockers solution. Solutions were applied to DRG neurons using an array of quartz fibers positioned near the cell after lifting the cell from the coverslip; solution exchange was estimated at $<1$ s. For results using either set of external solutions, the camphor and capsaicin currents are reported as net current densities, with the average basal currents of approximately three preceding current ramps subtracted from the peak agonist response. The camphor-activated currents in HEK cells were quite large in amplitude relative to the small basal current and are reported as total current density.

For experiments addressing the temperature activation of TRPV1 in HEK cells (see Fig. 9), the perfusate was heated using a Warner TC-325B temperature controller and a SH-27B solution heater as described previously (Xu et al., 2002). Temperature was recorded with a thermistor placed $<0.5 \mathrm{~mm}$ from the patched cell. All other experiments were conducted at room temperature $\left(\sim 21-23^{\circ} \mathrm{C}\right)$.

Cells were voltage clamped using an Axopatch 200B amplifier, controlled by a Digidata 1320 or 1322 and pClamp 9.0 or 9.2 software (Molecular Devices, Union City, CA). Recordings from HEK cells were acquired at $4 \mathrm{kHz}$ and filtered at $2 \mathrm{kHz}(-3 \mathrm{~dB}$; four-pole Bessel); DRG neuron recordings were acquired at $20 \mathrm{kHz}$ and filtered at $5 \mathrm{kHz}$. Wholecell capacitance was recorded from the amplifier settings or calculated by integrating the average of $12-16$ responses (filtered at $20 \mathrm{kHz}$ ) to a $40 \mathrm{~ms}$ step from -60 to $-70 \mathrm{mV}$. Capacity current was reduced as much as possible using the amplifier circuitry; series resistance compensation was $60-85 \%$. Voltage ramps ( $400 \mathrm{~ms}$ ) from -100 to $+100 \mathrm{mV}$ were applied every $4 \mathrm{~s}$ from a holding potential of $-60 \mathrm{mV}$. For Figures $3(G, H), 10$, and 11 , voltages were corrected by $-13 \mathrm{mV}$ to account for the liquid junction potential between the Cs-aspartate internal solution, measured using a flowing $3 \mathrm{M} \mathrm{KCl}$ bridge as described by Neher (1992). For all other recordings, the liquid junction potential was $-11 \mathrm{mV}$ but not corrected. All recordings were analyzed with pClamp, Origin 7 (OriginLab, Northampton, MA), Igor Pro 5.03 (Wavemetrics, Lake Oswego, OR), and Data Access 8.1 (Bruxton, Seattle, WA).

$\mathrm{Ca}^{2+}$ imaging. HEK cells were loaded with $5 \mu \mathrm{M}$ fura-2 AM in culture medium at $37^{\circ} \mathrm{C}$ for $60 \mathrm{~min}$. Cells were then washed in standard Tyrode's solution for 10-30 min. We used a MetaFluor imaging system (Universal Imaging Corporation, West Chester, PA) to record the fluorescence at different excitation wavelengths. GFP fluorescence was monitored with an excitation wavelength of $440 \mathrm{~nm}$ (F440). Fura-2 ratios (F340/F380) were recorded to reflect the changes in $\left[\mathrm{Ca}^{2+}\right]_{\mathrm{i}}$ after stimulation. 
Reagents. Camphor was prepared in a stock solution of $2 \mathrm{~m}$ (in DMSO), after accounting for an increase $(\sim 20 \%)$ in volume after the addition of camphor powder. Because of the low solubility of camphor in aqueous solutions, external solutions with 1-10 mM camphor required prolonged shaking ( $\sim 20 \mathrm{~min}$ ) and warming to $\sim 37^{\circ} \mathrm{C}$ to ensure a complete dissolution. Camphor solutions higher than $10 \mathrm{~mm}$ could not be completely dissolved.

Camphor, capsaicin, capsazepine, menthol, mustard oil (allyl isothiocyanate), 4- $\alpha$-phorbol didecanoate (4- $\alpha \mathrm{PDD})$, carbachol, 2-aminoethoxydiphenyl borate (2APB), and diphenylboronic anhydride (DPBA) were obtained from Sigma (St. Louis, MO). TTX, nimodipine, and phorbol-12-myristate-13-acetate (PMA) were obtained from Calbiochem (La Jolla, CA), $\omega$-conotoxin GVIA was obtained from Bachem (Torrance, CA), and $\omega$-AgaIVA was obtained from Peptides International (Louisville, KY).

Data analysis. Group data are presented as mean \pm SEM. Statistical comparisons were made using the ANOVA test. $p<0.05$ was considered statistically significant.

\section{Results}

\section{Camphor activates TRPV1 and TRPV3 heterologously expressed in mammalian cell lines}

To test the hypothesis that camphor excites sensory neurons by acting on specific TRP channels, we overexpressed several TRP channels related to sensory functions in HEK cells stably expressing the muscarinic M1 receptor or HEK293T cells. A whole-cell patch clamp was used to record the currents induced by bath application of camphor or other reagents. In cells transfected with rTRPV1, immediately after break-in we usually observed a constitutive current that was outwardly rectifying (with very small inward current) and declined to a steady state in $\sim 10-100$ s. In rTRPV1-expressing cells, we found that perfusion with a bath solution containing camphor readily increased both inward and outward currents during voltage ramps (400 ms) from -100 to $+100 \mathrm{mV}$. At least two types of stereoisomer camphors exist: $(+)$-camphor and $(-)$-camphor (Fig. 1A). Both isomers were able to induce rTRPV1-mediated currents $\left(I_{\mathrm{rTRPV} 1}\right)$ (Fig. $\left.1 B\right)$ that had broadly similar kinetics and amplitudes. Because neither isomer appeared to be a better agonist, we used $(+)$-camphor for all of the remaining experiments. Borneol is a botanical compound with a similar structure to camphor, and we found that borneol also weakly activated rTRPV1 (data not shown). Removal of $\mathrm{Ca}^{2+}$ (low $\mathrm{Ca}^{2+}$ solution, $1 \mathrm{~mm}$ EGTA replaced $2 \mathrm{mM} \mathrm{CaCl}_{2}$; see Materials and Methods) from the bath solution further increased the current amplitude of camphor-induced $I_{\text {rTRPV1 }}$ (data not shown). As expected, rTRPV1 was also activated by capsaicin (1 $\mu \mathrm{M})$ or anandamide $(10 \mu \mathrm{M})$, and the anandamide-activated current was inhibited by capsazepine (a competitive rTRPV1 antagonist; $10 \mu \mathrm{M}$ ) (Fig. 1C). To investigate the voltage dependence of camphor-induced $I_{\text {rTRPVl}}$, we used a voltage step protocol from -120 to $+140 \mathrm{mV}$ (Fig. $1 \mathrm{D}$, top). Significant changes in the kinetics of $I_{\text {rTRPV1 }}$ were observed at both depolarized and hyperpolarized potentials (Fig. $1 D$, bottom two panels).

Camphor activation of rTRPV1 was dose dependent (Fig. $2 \mathrm{~A}-$ $C)$. When low concentrations of camphor (1-3 mM) were added to rTRPV1-expressing cells, the outward currents increased to a greater extent than the inward currents. At $1 \mathrm{~mm}$ camphor, the peak current densities were $-4.7 \pm 2.0 \mathrm{pA} / \mathrm{pF}$ (mean $\pm \mathrm{SEM} ; n=$ $8)$ at $-60 \mathrm{mV}$ and $59 \pm 28 \mathrm{pA} / \mathrm{pF}(n=8)$ at $+60 \mathrm{mV}$. At $3 \mathrm{~mm}$ camphor, such values increased to $-17 \pm 8 \mathrm{pA} / \mathrm{pF}(n=8)$ at -60 $\mathrm{mV}$ and $165 \pm 55 \mathrm{pA} / \mathrm{pF}$ at $+60 \mathrm{mV}$. At higher concentrations of camphor $(10 \mathrm{~mm})$, large inward and outward currents were clearly activated (Fig. 2A-C). Although the concentrations of camphor required to activate TRPV1 are high, the activation is likely to be physiologically relevant, because camphor is used in
A

B

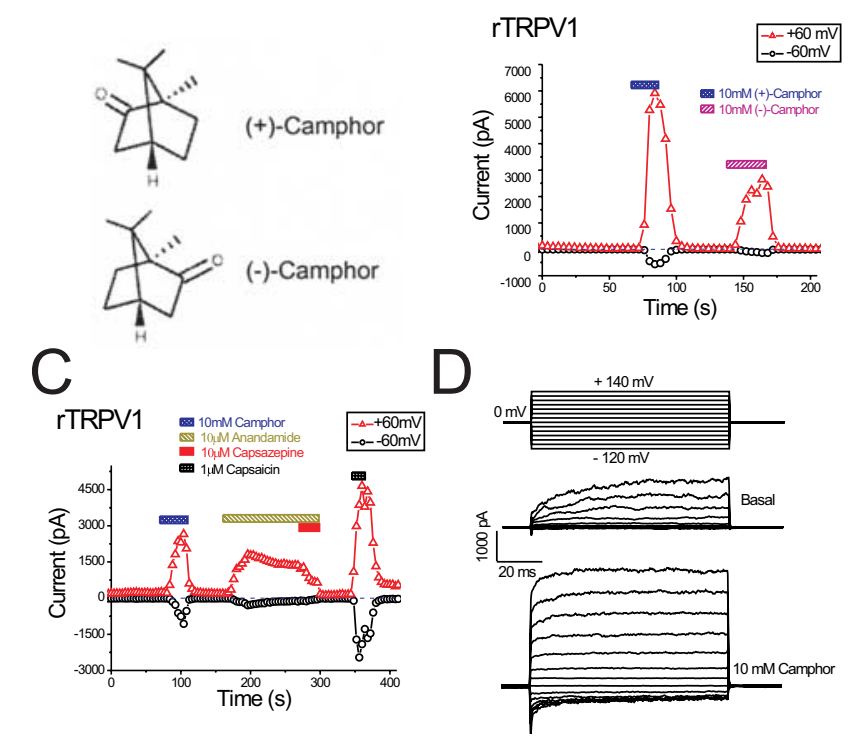

Figure 1. Camphor activates heterologously expressed rat TRPV1. $\boldsymbol{A}$, Structure of the $(+)$ and $(-)$ stereoisomers of camphor. $\boldsymbol{B}$, Both camphor stereoisomers activated rTRPV1. The weaker action of $(-)$-camphor in comparison with $(+)$-camphor was likely the result of tachyphylaxis. Ramp currents were evoked by $400 \mathrm{~ms}$ voltage ramps from -100 to $+100 \mathrm{mV}$ applied every $4 \mathrm{~s}$. Each symbol represents the current amplitude at $+60 \mathrm{mV}$ (red triangles) and $-60 \mathrm{mV}$ (black circles). Note the zero current level (indicated by blue dashed line). C, rTRPV1 was activated by camphor, anandamide, and capsaicin. Capsazepine $(10 \mu \mathrm{m})$ strongly inhibited the anandamide-induced currents. D, Effect of camphor on rTRPV1-mediated current elicited by voltage steps (protocol shown in the top panel).

topical preparations up to $11 \%$, corresponding to several hundred millimolar ( $600 \mathrm{~mm})$. Camphor activation of rTRPV1 did not saturate during application of up to $10 \mathrm{~mm}$ camphor; we did not study the effects of camphor at additional higher concentrations caused by the limited aqueous solubility of camphor (see Materials and Methods). The peak current densities at $10 \mathrm{~mm}$ camphor were $-135 \pm 56 \mathrm{pA} / \mathrm{pF}(n=8)$ at $-60 \mathrm{mV}$ and $508 \pm$ $79 \mathrm{pA} / \mathrm{pF}(n=8)$ at $+60 \mathrm{mV}$. DMSO at $0.5 \%$, the amount in the bath solution containing $10 \mathrm{~mm}$ camphor, failed to activate any significant current from TRPV1-expressing cells (data not shown). These results suggest that camphor activates rTRPV1 in the millimolar range, with a distinct concentration dependence at positive $(+60 \mathrm{mV})$ and negative $(-60 \mathrm{mV})$ potentials. One possible explanation for the enhanced response at positive potentials is that camphor activation results from a leftward shift of the voltage dependence of TRPV1 channels to a position in which the open probability of the channel is higher at depolarized potentials than at hyperpolarized potentials. A similar mechanism has been proposed for heat and capsaicin activation of TRPV1 (Gunthorpe et al., 2000; Ahern and Premkumar, 2002; Voets et al., 2004) and also for the activation of TRPM8 by cold and menthol (Brauchi et al., 2004; Voets et al., 2004). The camphor-induced shift of the voltage dependence appeared to be large, but because the basal currents did not reach saturation, the numerical value of the shift could not be legitimately determined from the standard $G-V$ curves.

We also found that camphor activated TRPV3, similar to a recent report by Moqrich et al. (2005) (Fig. 2D-F). No current or very small outward currents were seen at low concentrations of camphor (1-3 mM) in mTRPV3-expressing cells. However, application of $10 \mathrm{~mm}$ camphor activated a large TRPV3-mediated 

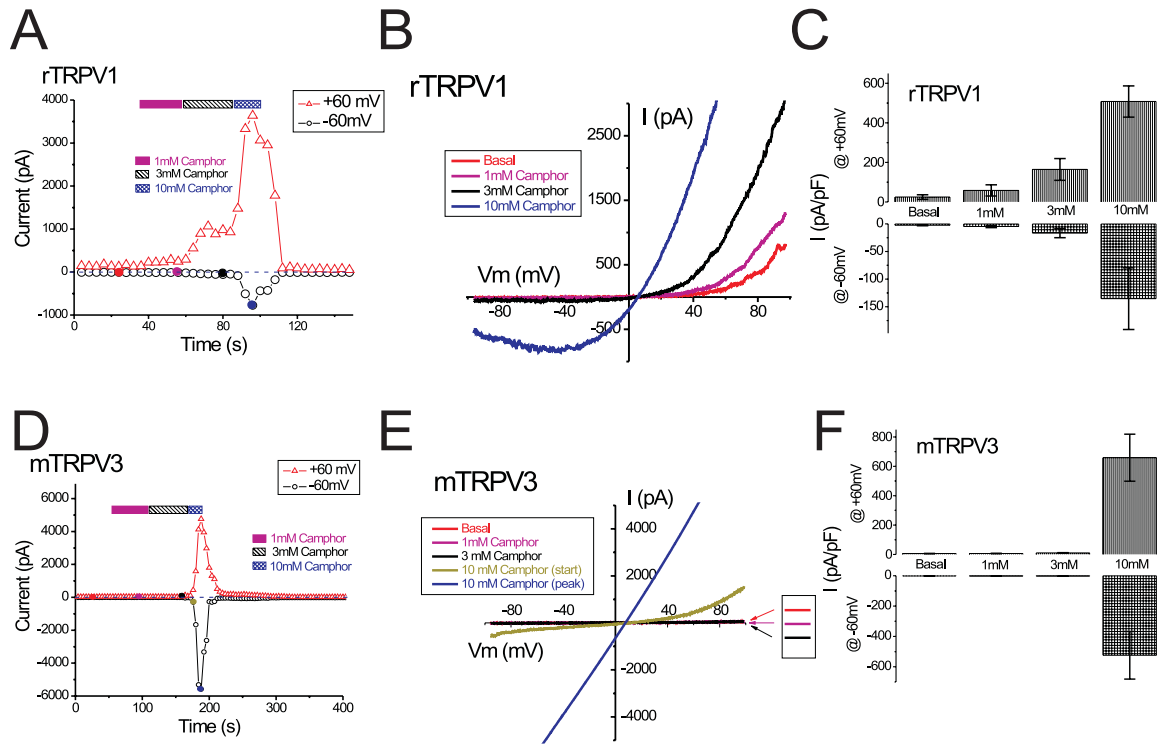

Figure 2. Camphor activates TRPV1 at lower concentrations than TRPV3. $\boldsymbol{A}$, Concentration dependence of the activation of TRPV1 by camphor (1, 3, and $10 \mathrm{~mm}$ ). Representative ramp currents shown in $\boldsymbol{B}$ correspond to the filled circles with the same color in $\boldsymbol{A}$. Note the negative slope in the inward current during the ramp, characteristic of $I_{\text {TRPV1 }}$. $\boldsymbol{C}$, Average TRPV1 current densities (current amplitude normalized to the capacitance of each cell; $\mathrm{pF}$ ) elicited by 1-10 mm camphor. Data are shown as mean \pm SEM. $\boldsymbol{D}-\boldsymbol{F}$, Concentration dependence of the activation of TRPV3 by 1-10 mm camphor. The representative ramp currents are shown in $\boldsymbol{E}$. Note the change of rectification during the development of $I_{\text {TRPV3 }}$ after camphor application, as the peak current became linear. $\boldsymbol{F}$, Average $I_{\text {TRPV } 3}$ density induced by different concentrations of camphor.

current $\left(I_{\mathrm{TRPV} 3}\right)$, with peak current densities of $-524 \pm 157$ $\mathrm{pA} / \mathrm{pF}$ at $-60 \mathrm{mV}$ and $659 \pm 160 \mathrm{pA} / \mathrm{pF}$ at $+60 \mathrm{mV}(n=6)$. At the onset of $10 \mathrm{~mm}$ camphor application, the TRPV3 ramp current was either outwardly rectifying or doubly rectifying, but the peak current usually became linear over time (Fig. $1 H$ ). This increase in linearity did not result from nonspecific membrane leak; ruthenium red, a voltage-dependent blocker of TRPV1-4 channels (Voets et al., 2002; Chung et al., 2004), selectively inhibited the camphor-induced inward TRPV3 current at $10 \mu \mathrm{M}$ (data not shown). At intermediate concentrations of camphor (4 or 5 $\mathrm{mM})$, smaller rectifying currents were seen. These results suggest that camphor activated TRPV3 with a very steep dose dependence, potentially analogous to the steep temperature dependence of TRPV3 activation (Peier et al., 2002b; Smith et al., 2002; $\mathrm{Xu}$ et al., 2002). The poor solubility of camphor in the standard bath solution (see Materials and Methods) may complicate our analysis. However, an underestimation of [camphor] at higher levels would reduce, rather than increase, the steepness of the dose dependence. Such a sharp dose dependence was only observed for the naive response of camphor activation. Repeated applications of camphor sensitized TRPV3 to lower concentrations of camphor. TRPV1, TRPV2, and TRPV3 channels are activated by $2 \mathrm{APB}$ or DPBA by unknown mechanisms (Hu et al., 2004; Chung et al., 2005). Camphor dose dependence was altered when we applied short exposures of $100 \mu \mathrm{M} 2 \mathrm{APB}$ or DPBA to the cells before camphor treatment. In these cases, 1-3 mM camphor rapidly activated large $I_{\mathrm{TRPV} 3}$ (data not shown). These results suggest that camphor activated both rTRPV1 and mTRPV3 but with distinct dose dependencies.

TRPV1 and TRPV3 channels are $\mathrm{Ca}^{2+}$-permeable channels (Clapham, 2003), and thus their activation by camphor should lead to a rise in $\left[\mathrm{Ca}^{2+}\right]_{\mathrm{i}}$. We tested this possibility by performing $\mathrm{Ca}^{2+}$ imaging experiments (Fig. 3A-F). Cells expressing TRPV1EGFP, TRPV2-EGFP, or TRPV3-EGFP fusion proteins were loaded with fura-2, and fluorescence ratios (F340/F380) were measured before and after the addition of camphor. Camphor (5 $\mathrm{mm}$ ) application led to negligible increases in fura-2 ratios of EGFP-negative cells (Fig. $3 A-F$ ) or vector-transfected cells (data not shown). However, significant increases of fura-2 ratios were induced by camphor $(5 \mathrm{mM})$ in rTRPV1-expressing cells (Fig. $3 A, B$ ) as well as in mTRPV3-expressing cells (Fig. $3 E, F)$. No apparent increase was seen in rTRPV2-expressing cells (Fig. 3C,D). TRPV2-expressing cells did respond to 200-500 $\mu \mathrm{M}$ DPBA (Fig. 3C,D), a common agonist for TRPV1, TRPV2, and TRPV3 channels (Chung et al., 2005).

\section{Camphor inhibits rat TRPA1 and fails to activate several other related TRP channels heterologously expressed in HEK cells}

TRPV1 and TRPV3 are members of the vanilloid TRP subfamily, sharing the most significant structural and functional similarities with TRPV2 and TRPV4. To determine whether camphor is able to activate these related channels, we expressed rat TRPV2 and mouse TRPV4 in HEK cells and recorded currents in response to the addition of $10 \mathrm{~mm}$ camphor. No noticeable current was induced by camphor in TRPV2-transfected cells during ramp voltages $(-100$ to $+100 \mathrm{mV})$, although in the same cells, robust activation of doubly rectifying or linear current could be elicited by the addition of $300 \mu \mathrm{M}$ DPBA (Fig. $4 A, B$ ) in the presence (data not shown) or absence of camphor. Similarly, heterologously expressed mTRPV4 was not activated in response to $10 \mathrm{~mm}$ camphor application (Fig. 4C,D). Indeed, camphor appeared to block the constitutive current in these cells (Fig. 4C,D). TRPV4 currents could be elicited by application of $1 \mu \mathrm{M} 4-\alpha \mathrm{PDD}$, an agonist of TRPV4 (Watanabe et al., 2002). Together, camphor specifically activates TRPV1 and TRPV3 but not the closely related TRPV2 and TRPV4.

We next examined whether camphor is able to activate other members of the TRP channel superfamily more distantly related to TRPV channels. TRPM8 is a member of the TRPM subfamily that is activated by cold temperatures and menthol (McKemy et al., 2002; Peier et al., 2002a), and TRPC5 is a member of the TRPC subfamily that is activated downstream of phospholipase $\mathrm{C}$ (PLC)-couple receptor activation (Schaefer et al., 2000). HEK cells expressing both of these channels typically displayed some constitutive basal currents at positive potentials (Fig. $4 E-H$ ). We found that application of $10 \mathrm{~mm}$ camphor did not activate currents in these cells but rather appeared to inhibit the constitutive currents. Much larger currents could be elicited in these cells by the addition of menthol ( $500 \mu \mathrm{M})$ to TRPM8-expressing cells and carbachol $(100 \mu \mathrm{M})$ to TRPC5-expressing HEK293T cells cotransfected with the human muscarinic type 1 receptor.

TRPA1 is a channel expressed in a large subset $(\sim 30-50 \%)$ of DRG sensory neurons that also express TRPV1 (Story et al., 2003; Jordt et al., 2004), which includes many nociceptive neurons (Nagata et al., 2005). In HEK cells expressing the rat isoform of TRPA1, we observed constitutive currents, which declined to a steady state $\sim 10-100 \mathrm{~s}$ after break-in (Fig. $5 A, B$ ). These TRPA1mediated basal currents $\left(I_{\text {TRPA1 }}\right)$ exhibited weakly double- 
A

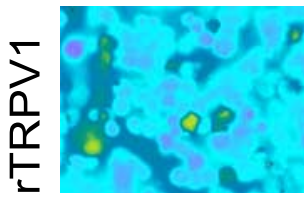

Basal

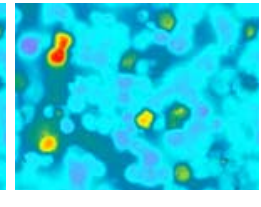

Camphor

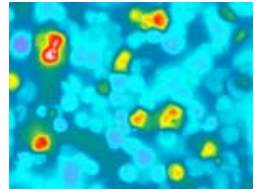

Capsaicin

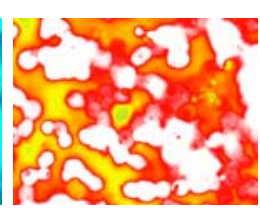

lonomycin
B
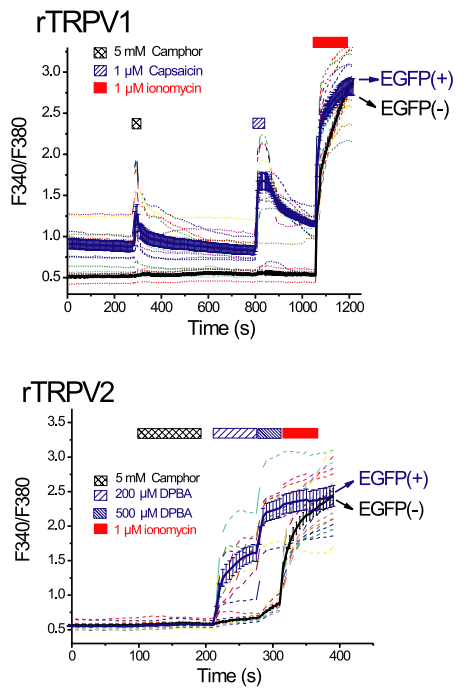

mTRPV3

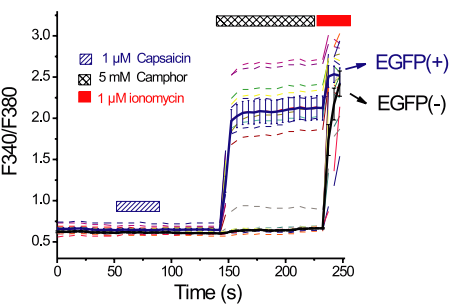

Figure 3. Camphor induces $\left[\mathrm{Ca}^{2+}\right]_{\mathrm{i}}$ rise in TRPV1- and TRPV3-expressing cells but not in TRPV2-expressing cells. $\boldsymbol{A}$, Camphor and capsaicin increased fura-2 ratios (F340/F380) of HEK cells transfected with the rTRPV1-EGFP construct. EGFP-positive cells were identified by measuring F440. TRPV1-positive cells had higher fura-2 ratios under resting states, indicative of higher basal $\left[\mathrm{Ca}^{2+}\right]_{\mathrm{i}}$ level. Camphor (5 mM) increased fura-2 ratios in most of these TRPV1-positive (expressing) cells with no, or only very minimal, effects on TRPV1-negative cells. Capsaicin (1 $\left.\mu \mathrm{m}\right)$ induced increases of fura-2 ratios in almost all of the TRPV1-positive cells. All cells responded to $\mathrm{Ca}^{2+}$ ionophore ionomycin (1 $\left.\mu \mathrm{M}\right)$. B, Average changes (mean \pm SEM; solid line) in the fura-2 ratio induced by camphor and capsaicin in TRPV1-positive cells (blue) and TRPV1-negative cells (black). Responses from individual cells were plotted in dotted lines of various colors. $C, \boldsymbol{D}$, Camphor (5 mM) failed to increase fura-2 ratios in TRPV2-positive cells. The same cells responded with 200-500 $\mu \mathrm{m} \mathrm{DPBA,} \mathrm{an} \mathrm{agonist} \mathrm{of} \mathrm{TRPV1-3} \mathrm{channels.} \mathrm{E,} F$, TRPV3-expressing cells responded strongly to camphor (5 $\mathrm{mm}$ ) but not to capsaicin (1 $\mu \mathrm{M})$.

rectifying or quasi-linear current-voltage relationships (Fig. 5B). As expected (Jordt et al., 2004), $I_{\text {TRPA1 }}$ was activated by $200 \mu \mathrm{M}$ mustard oil (allyl isothiocyanate) (Fig. 5A,B). Surprisingly, 10 mM camphor completely suppressed $I_{\text {TRPAl }}$ (Fig. 5A-C). Constitutive currents in TRPA1-expressing cells were large and had stable amplitudes, which allowed us to measure the inhibition of TRPA1 at several concentrations of camphor. At $-80 \mathrm{mV}$, camphor $(10 \mathrm{mM})$ strongly reduced $I_{\text {TRPA } 1}$ from $-16.7 \pm 3.0 \mathrm{pA} / \mathrm{pF}$ $(n=6)$ to $-2.77 \pm 0.9 \mathrm{pA} / \mathrm{pF}(n=6)$. This inhibition was not caused by $0.5 \%$ DMSO and was quickly reversible within $12 \mathrm{~s}$. Obvious inhibition was also seen at much lower concentrations than required to activate TRPV1 and TRPV3 channels (Fig. 2). Half-maximal inhibition $\left(\mathrm{IC}_{50}\right)$ occurred at a concentration of $0.66 \mathrm{~mm}$ camphor, with a Hill slope of 0.94 ( $n=6$ cells). These results suggest that camphor strongly inhibits TRPA1. Although the precise role of TRPA1 channels in nociception is still unclear, inhibition of TRPA1 might play a role in the analgesic properties of camphor.

\section{Camphor sensitivity of TRPV1 is segregated from capsaicin sensitivity}

Most chemical agonists of TRPV1 share structural similarity, often containing a vanilloid moiety, and activate TRPV1 via a similar mechanism (Jordt and Julius, 2002). Although camphor does not contain a vanilloid group, it is quite hydrophobic and could plausibly interact with TRPV1 channels at the same locus [i.e., transmembrane domains 2-4 (TM2-4)] (Jordt and Julius, 2002). To investigate whether camphor activates rTRPV1 through a vanilloid-dependent mechanism, we studied the effects of camphor on vanilloid-insensitive TRPV1 isoforms. The chicken isoform of TRPV1 (cTRPV1) is also activated by low $\mathrm{pH}$ and heat, yet it is almost completely insensitive to capsaicin (Jordt and Julius, 2002). Interestingly, we found that camphor (10 mM) also failed to activate cTRPV1 (Fig. 6A,B). Indeed, the small constitutive outward currents were reversibly inhibited (Fig. 6B), similar to what we have seen in other TRP channels with basal currents (Figs. 4, 5).

Chicken TRPV1 can be rendered capsaicin sensitive if TM2-4 are replaced by the corresponding part of rTRPV1 [chicken-rat chimeric TRPV1 (crcTRPV1) or V2-4C] (Fig. 6C) (Jordt and Julius, 2002). However, the camphor was still unable to activate this chimeric channel (Fig. $6 C, D$ ), suggesting that the molecular determinants of camphor sensitivity of TRPV1 are located in a region of the channel distinct from TM2-4. In agreement with this, camphor activation persisted in a point mutant of rTRPV1, Y511A-rTRPV, which nearly abolishes capsaicin activation (Jordt and Julius, 2002) (Fig. 6E,F). Furthermore, we observed robust camphor induction in rTRPV1-expressing cells even in the presence of $10 \mu \mathrm{M}$ capsazepine (Fig. $6 G, H$ ), which is a competitive inhibitor at the vanilloid binding site (Jordt and Julius, 2002). In these experiments, $3 \mathrm{~mm}$ instead of $10 \mathrm{~mm}$ camphor was used to minimize desensitization of TRPV1. Inhibition of the camphor-activated TRPV1 inward current 
A

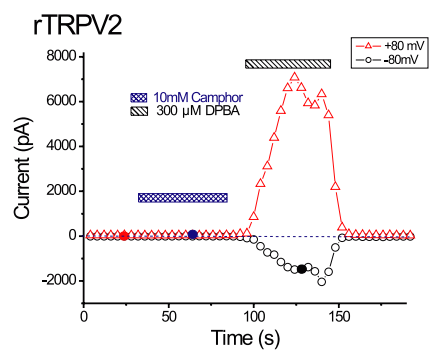

$E$

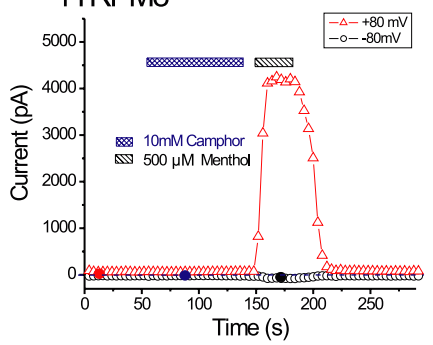

B C
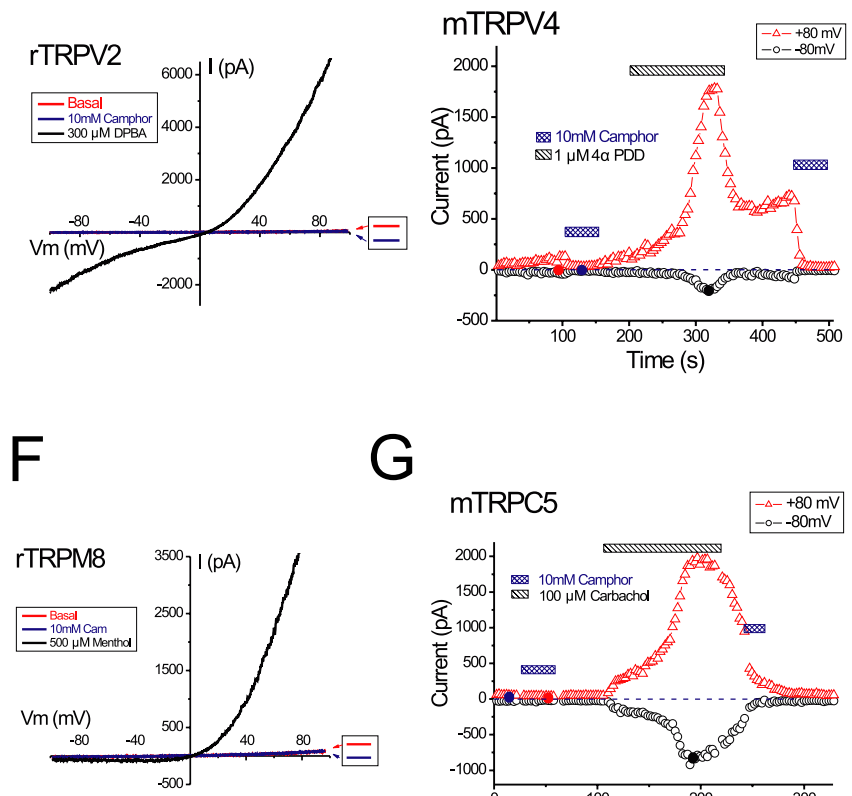

D

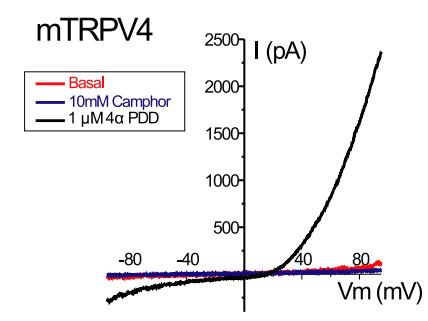

$\mathrm{H}$
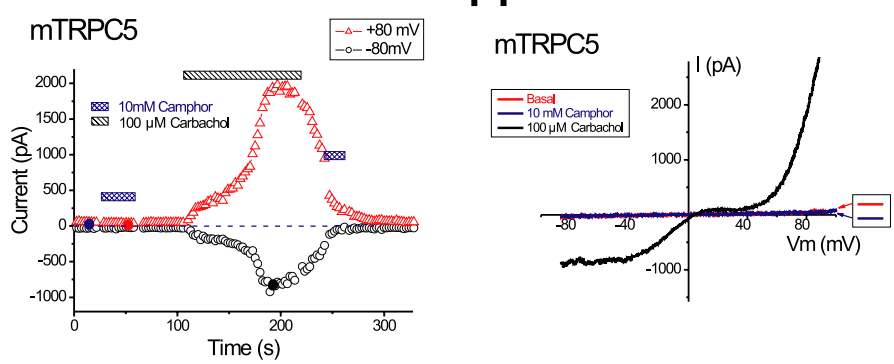

Figure 4. Camphor does not activate currents in cells expressing several related TRP channels. $A, B$, Camphor (10 mM) did not activate current from a TRPV2-expressing cell. The expression of TRPV2 was confirmed by the response induced by $300 \mu \mathrm{m}$ DPBA. C, $\boldsymbol{D}$, Camphor (10 mM) failed to increase the basal current from a TRPV4-transfected cell. Indeed, the small constitutive activity was completely inhibited. 4- $\alpha$ PDD $(1 \mu \mathrm{M})$ readily activated a doubly rectifying current characteristic of $I_{\text {TRPV4. }}$ E, $F$, TRPM8 was not activated by $10 \mathrm{~mm}$ camphor but by $500 \mu \mathrm{m}$ menthol. A small outward-rectifying basal current was seen after break in (data not shown) but decayed almost completely. $\mathbf{G}, \boldsymbol{H}$, Application of $10 \mathrm{~mm}$ camphor to a cell cotransfected with mTRPC5 and the M1 receptor did not activate TRPC5 currents $\left(I_{\text {TRPC5 }}\right)$. Subsequent application of $100 \mu \mathrm{m}$ carbachol activated large inward and outward currents with the characteristic $I-V$ of $I_{\text {TRPC5 }}$.

A

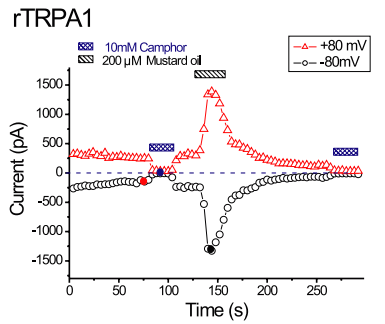

B

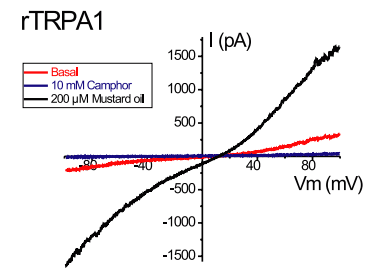

C

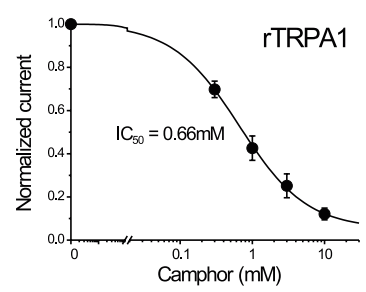

Figure 5. Camphor inhibits TRPA1-mediated basal currents. $\boldsymbol{A}, \boldsymbol{B}$, The basal TRPA1 activity was reversibly inhibited by camphor. $I_{\text {TRPA } 1}$ was stimulated by $200 \mu \mathrm{m}$ mustard oil (allyl isothiocyanate). $C$, Dose dependence of camphor-induced inhibition of basal $I_{\text {TRPA1 }}$ (measured at $-80 \mathrm{mV} ; n=6$ ). Data were fitted with a sigmoid curve with an $\mathrm{IC}_{50}$ value of $0.66 \mathrm{~mm}$ and a Hill coefficient of 0.94 .

was nearly complete with $10 \mu \mathrm{M}$ ruthenium red, which acts by binding in the channel pore (Garcia-Martinez et al., 2000), resulting in strong voltage-dependent block (Fig. $6 H$ ). All of these results suggest that camphor activates TRPV1 by interacting with sites distinct from those important for capsaicin and other vanilloid agonist actions.

\section{Camphor-induced TRPV1 currents exhibit strong acute desensitization and tachyphylaxis}

TRPV1 exhibits two types of desensitization response to activation: acute desensitization, during which TRPV1 currents decline despite the continued presence of agonist, and tachyphylaxis, in which repeated short-duration applications of agonist lead to smaller responses (Koplas et al., 1997; Bhave et al., 2002). Agonists of TRPV1 can induce a long-lasting analgesic effect after an initial activation; this analgesic effect can be especially pronounced in inflammatory conditions (Menendez et al., 2004). TRPV1 desensitization mechanisms may contribute to this anal-

gesic effect of TRPV1 agonists (Koplas et al., 1997; Bhave et al., 2002). It is conceivable that desensitization of camphorinduced rTRPV1-mediated currents may also contribute to the analgesic properties of camphor. When camphor was applied to rTRPV1-expressing cells for $>60 \mathrm{~s}, I_{\mathrm{r}^{-}}$ TRPV1 exhibited significant acute desensitization. Although desensitization was typically weak at $3 \mathrm{~mm}$ camphor (Fig. $2 A, B$ ), complete desensitization was nearly always seen at $10 \mathrm{~mm}$ concentrations within tens of seconds after camphor exposure (Fig. $7 A, B$ ). The amount of TRPV1 desensitization induced by exposure to $1 \mu \mathrm{M}$ capsaicin (measured in the same cell $\sim 60 \mathrm{~s}$ after removal from camphor) was much weaker than that induced by camphor (Fig. 7A). The kinetics of camphor-induced acute desensitization varied significantly from cell to cell with $\sim 10$ to $\sim 90 \%$ desensitization developing over 30 s after reaching the peak. We noticed that both the kinetics and extent of desensitization resulting from camphor application were most profound in those cells that had the largest amplitude of inward currents, perhaps reflecting the amount of $\mathrm{Ca}^{2+}$ influx. The importance of inward current amplitude in controlling capsaicininduced desensitization has been shown previously (Bhave et al., 2002). In those cells with $>500 \mathrm{pA}$ inward current elicited by camphor, $I_{\text {rTRPV } 1}$ desensitized by $90 \%$ during $29 \pm 4$ s $(n=7)$ application. In contrast, the capsaicin-induced desensitization was only $25 \pm 3 \%(n=4)$ when measured in this time frame (28 $\mathrm{s}$ after capsaicin addition). Because of the strong acute desensitization, we adopted protocols for the minimal (withdrawing the 

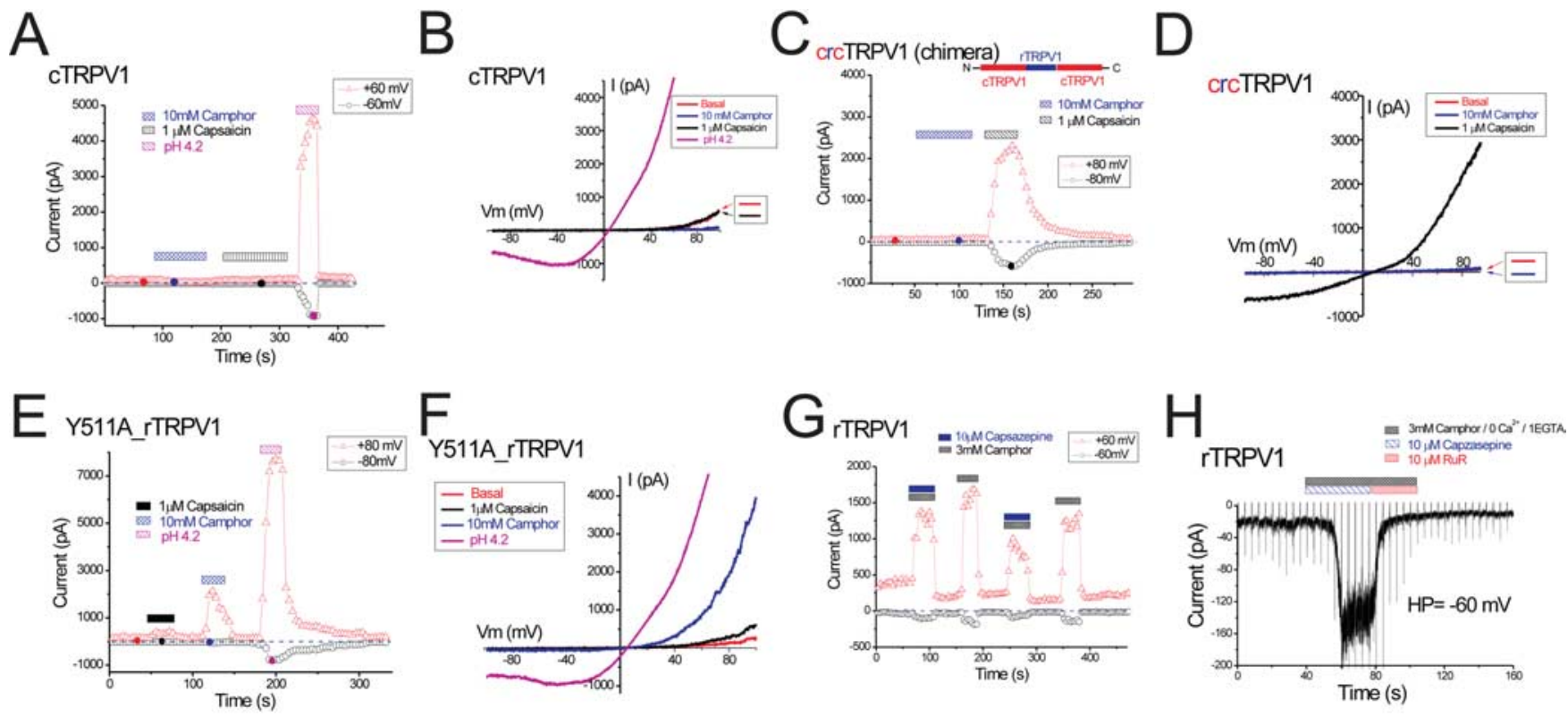

Figure 6. Camphor does not activate TRPV1 by a vanilloid-dependent mechanism. $A, B$, Chicken TRPV1 was not activated by camphor or capsaicin. Application of low pH (pH 4.2) solution did activate an outwardly rectifying cTRPV1-mediated current. $\boldsymbol{C}, \boldsymbol{D}$, A rat-chicken chimeric TRPV1 (schematic structure inset) was activated by capsaicin but not by camphor. $\boldsymbol{E}, \boldsymbol{F}, \mathrm{A}$ capsaicin-insensitive point mutant of rat TRPV1 (Y511A_rTRPV1) was only very weakly activated by capsaicin but retained apparently normal camphor sensitivity. G, Camphor activation of TRPV1 in the presence of 10 $\mu$ m capsazepine, a competitive inhibitor at the vanilloid binding site. A low concentration of camphor ( $3 \mathrm{~mm}$ ) was used here to minimize desensitization. $\boldsymbol{H}$, Camphor-induced inward $I_{\mathrm{rTRPV} 1}$ in the presence of capsazepine was completely inhibited by the pore blocker ruthenium red $(10 \mu \mathrm{M})$. Low $\mathrm{Ca}^{2+}$ solution was used here to minimize desensitization.

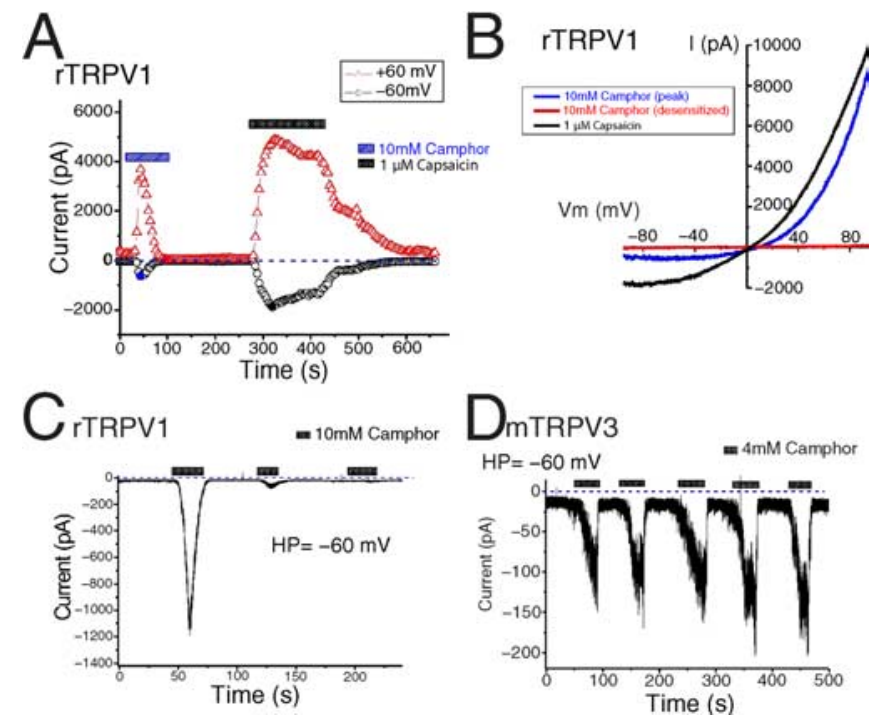

Figure 7. Camphor-activated $I_{\text {TTRPV } 1}$ exhibits fast acute desensitization and strong tachyphylaxis. $A, B, I_{\text {rTRPV } 1}$ activated by $10 \mathrm{~mm}$ camphor quickly and completely desensitized during an $\sim 60$ s application. Capsaicin-activated currents desensitized with much slower kinetics and less completely. C, Camphor-activated inward $I_{\mathrm{rTRPV} 1}$ underwent very strong tachyphylaxis, giving much smaller response on repeated applications of $10 \mathrm{~mm}$ camphor. $\boldsymbol{D}$, In contrast, $I_{\text {TRPV3 }}$ was slightly sensitized after repeated stimulation with $4 \mathrm{~mm}$ camphor.

stimulus once the current reached the peak) or maximal (constant application of the agonists until the current desensitized to a steady state) desensitization by controlling the durations of bath application of camphor. When $10 \mathrm{~mm}$ camphor was applied to cells for sufficient durations to generate maximal desensitization, subsequent applications of camphor elicited little or no TRPV1 current; in other words, tachyphylaxis was very strong (Fig. 7C). In contrast, $I_{\mathrm{TRPV} 3}$ typically exhibited sensitization during repetitive camphor applications (Fig. 7D) as reported previously (Moqrich et al., 2005).
To further analyze the desensitization properties of camphorinduced TRPV1 response, we studied the effects of camphor on the tachyphylaxis of proton or capsaicin-induced $I_{\mathrm{TRPV} 1}$. When two short-duration (minimal desensitization protocol) test exposures to low $\mathrm{pH}$ solutions, which were timed to produce little or no acute desensitization, were applied to TRPV1 expressing cells, $I_{\text {rTRPV } 1}$ recovered $94 \pm 6 \%(n=4)$ after a 5 min recovery period (Fig. $8 A, B, E$ ). We then applied $10 \mathrm{~mm}$ camphor for $\sim 5$ min, resulting in a smaller, transient current (maximal desensitization) (Fig. $8 \mathrm{~A}$ ). For the same set of cells, the recovery of the low $\mathrm{pH}$-elicited current dropped significantly, to only $6 \pm 3 \%(p<$ $0.001 ; n=4)$ (Fig. $8 E$ ) after camphor treatment (Fig. $8 A, B, E$ ). Camphor-induced inhibition of the TRPV1 channels persisted even after prolonged ( $>10 \mathrm{~min}$ ) washout (Fig. $8 \mathrm{~A}$ ). Similarly, camphor also strongly inhibited the recovery of capsaicininduced $I_{\text {rTRPV1 }}$ (Fig. 8D,E). After camphor exposure the capsaicin-elicited current was $23 \pm 4 \%(n=4)$, significantly $(p<0.001)$ lower than the untreated condition (in which recovery from multiple capsaicin applications was $91 \pm 8 \%$ ). These results suggest that camphor treatment dramatically intensified the tachyphylaxis of TRPV1 channels, despite the smaller inward current resulting from camphor application.

Interestingly, camphor-induced enhancement of tachyphylaxis was specific for rat TRPV1, and camphor did not alter chicken TRPV1 tachyphylaxis. For proton-induced $I_{\text {CTRPV1 }}$ (Fig. $8 C, E)$, the recovery subsequent to camphor treatment was $86 \pm$ $7 \%(n=4)$, not significantly $(p>0.05)$ different from the recovery to two low $\mathrm{pH}$ exposures applied before camphor $(91 \pm$ $7 \% ; n=4)$. Camphor did have the aforementioned inhibitory effect on the cTRPV1-mediated basal current (Fig. 8C). However, such inhibition quickly recovered after camphor removal $(<20 \mathrm{~s})$ (Fig. 8C), suggesting that the mechanisms for inhibiting the constitutive current differ from those for the long-lasting enhancement of tachyphylaxis. These results suggest that the camphorinduced strong tachyphylaxis requires activation of TRPV1. 

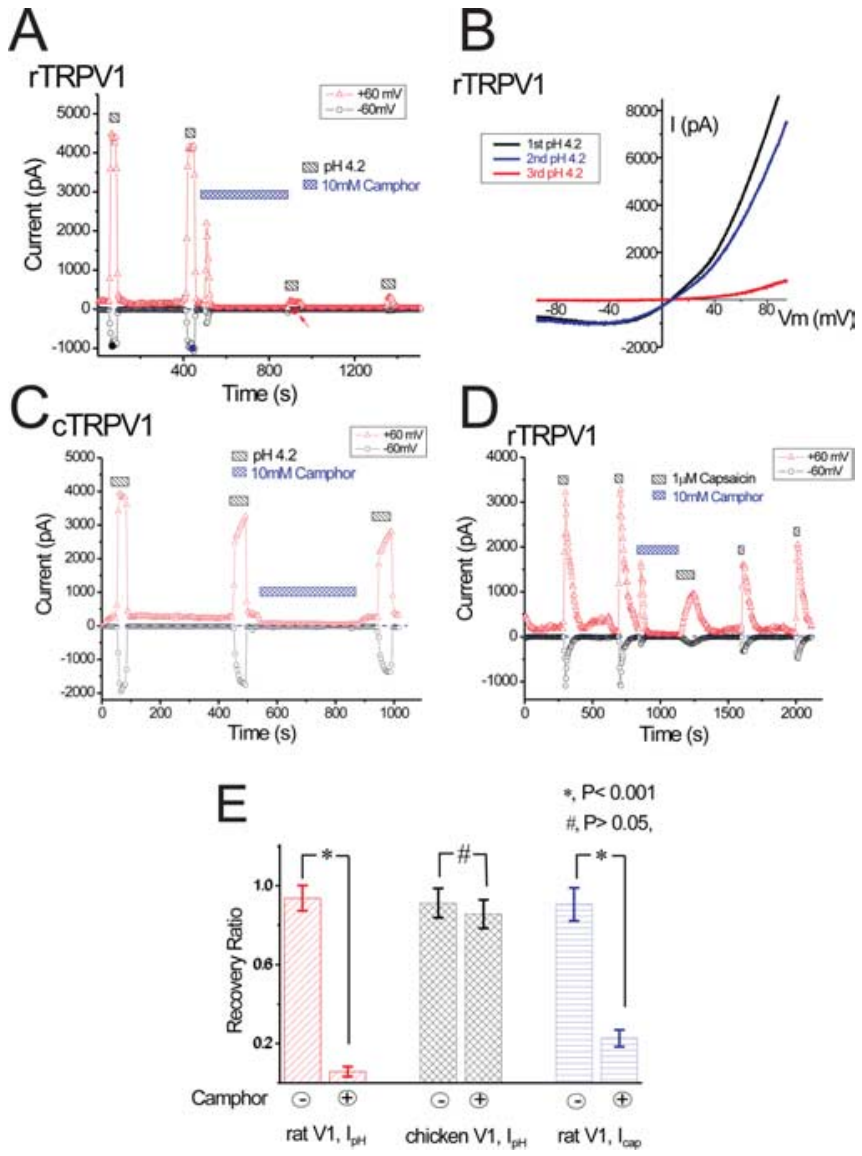

Figure 8. Camphor dramatically enhances tachyphylaxis of proton and capsaicin-activated TRPV1 current. $\boldsymbol{A}, \boldsymbol{B}$, Proton-activated $I_{\text {TRPVV } 1}$ recovered nearly completely during $5 \mathrm{~min}$ separating two exposures to low $\mathrm{pH}$ solution. $\mathrm{A} 5 \mathrm{~min}$ exposure to $10 \mathrm{~mm}$ camphor, applied between low-pH solutions, strongly reduced the TRPV1 current during the subsequent low-pH activation. Even prolonged washout did not result in substantial recovery. Note the transient camphor-induced current. $\boldsymbol{C}$, Proton-induced current from a cTRPV1-expressing cell was barely reduced by $5 \mathrm{~min}$ of camphor exposure. $\boldsymbol{D}$. Capsaicin-induced $I_{\mathrm{rTRPV} 1}$ was also attenuated by camphor application. $\boldsymbol{E}$, Summary of the effects of camphor on tachyphylaxis of proton and capsaicin-activated currents from chicken or rat TRPV1-expressing cells. The recovery ratio for two consecutive stimulations was defined as the percentage of the latter response relative to the initial. Recovery ratios for both proton-induced $I_{\text {rTRPV1 }}\left(\right.$ red) and capsaicin-induced $I_{\text {TRRVV1 }}$ (blue) exhibited significant difference with (+) or without (-) 5 min of camphor exposure $\left({ }^{*} p<0.001\right)$. There was no significant difference on the recovery of proton-induced $I_{\text {CTRPV } 1}$ (black; $\left.{ }^{*} p>0.05\right)$.

\section{Cross-sensitization of TRPV1 by camphor, heat, and receptor activation}

TRPV1 is a polymodal receptor for heat, proton, capsaicin, vanilloids, and endocannabinoids (Jordt et al., 2003). The interaction of camphor with the activation mechanisms of TRPV1 channels suggests that camphor may enhance the ability of other agonists to promote channel opening. A similar interaction occurs between capsaicin and proton activation of TRPV1 (Tominaga et al., 1998; Jordt et al., 2000). Like anandamide (Ross, 2003) and $N$-arachidonyl dopamine (NADA) (Premkumar et al., 2004), camphor appeared to be a partial agonist of TRPV1 (see Discussion), with substantial activation of the channel requiring millimolar concentrations. However, the efficacy of camphor could be increased if other TRPV1 agonists act on the channel synergistically, for example, at physiological temperatures and under inflamed conditions. To test this possibility, we applied 3 mM camphor to TRPV1-expressing cells after the temperature of the extracellular solution was raised to $34^{\circ} \mathrm{C}$. The temperature
A

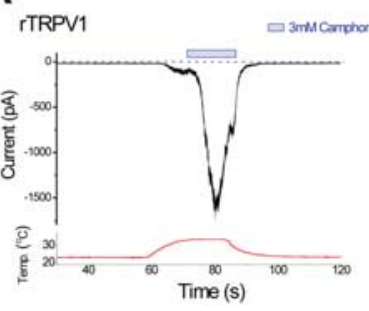

B

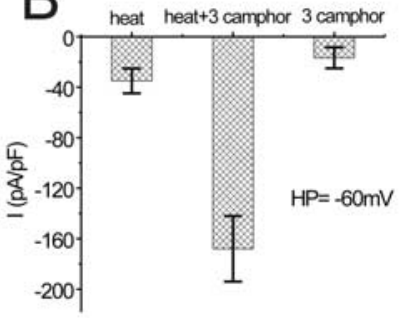

CirRPV

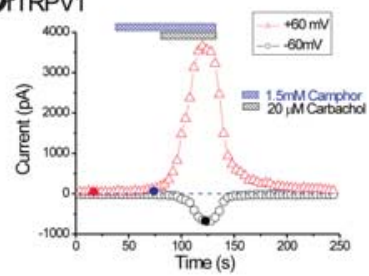

D
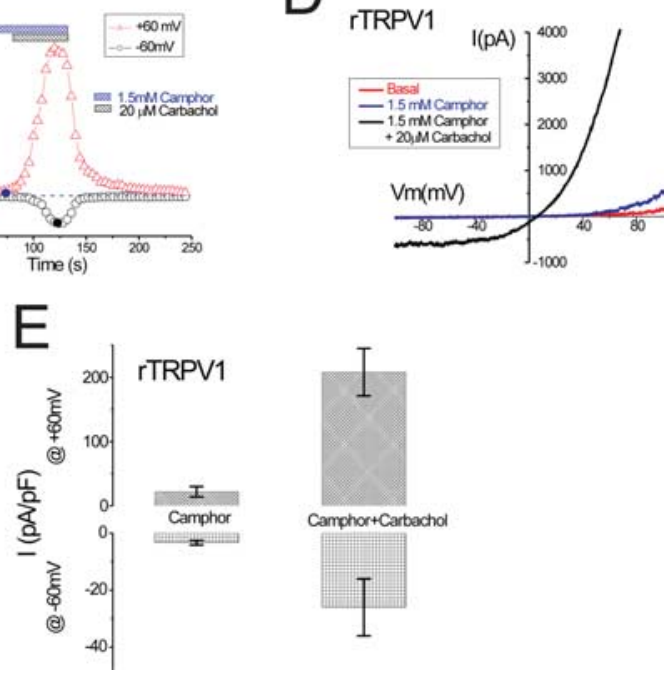

Figure 9. Camphor activation of rTRPV1 is enhanced at elevated temperatures and sensitized by receptor stimulation in HM1 cells. $A$, The effect of $3 \mathrm{~mm}$ camphor on $I_{\text {rTRPV } 1}$ at elevated temperatures. Temperature protocol is shown below. Camphor-induced $I_{\mathrm{rTRPV} 1}$ quickly desensitized after reaching its peak. $\boldsymbol{B}$, Average current densities elicited by elevated temperature and $3 \mathrm{~mm}$ camphor at warm temperatures $\left(\sim 33-35^{\circ} \mathrm{C}\right)$ are shown. The " 3 camphor" shows the average current density elicited by $3 \mathrm{~mm}$ camphor in a separate group of cells (Fig. 2C). C, In an rTRPV1-expressing HM1 cell, the small $I_{\text {rTRPV1 }}$ induced by $1.5 \mathrm{~mm}$ camphor was dramatically potentiated by $20 \mu \mathrm{m}$ carbachol application. The representative ramp current is shown in $\boldsymbol{D}$. $\boldsymbol{E}$, Summary of the effects of carbachol on camphor-activated $I_{\text {rTRPV1 }}$ at both -60 and $+60 \mathrm{mV}$.

increase alone activated a small inward current of approximately $-130 \mathrm{pA}$ at $-60 \mathrm{mV}$ (Fig. 9A). Application of $3 \mathrm{~mm}$ camphor to the same cell, in the continued presence of $34^{\circ} \mathrm{C}$ solution, dramatically enhanced the current (to approximately $-1600 \mathrm{pA}$ ). From five TRPV1-expressing cells, elevating the bath temperature to $34 \pm 1^{\circ} \mathrm{C}$ activated an inward current of $-35 \pm 9 \mathrm{pA} / \mathrm{pF}$ $(n=5)$ (Fig. 9B). Application of $3 \mathrm{~mm}$ camphor at the elevated temperature increased the current to an average of $-168 \pm 26$ $\mathrm{pA} / \mathrm{pF}$ at $-60 \mathrm{mV}(n=5)$. This current density was significantly higher than the $-17 \pm 8 \mathrm{pA} / \mathrm{pF}(n=8)$ current evoked by $3 \mathrm{~mm}$ camphor applied at $\sim 22^{\circ} \mathrm{C}$ in a separate group of cells $(p<$ 0.001 ) (Figs. 9B, 2C). The large enhancement of the camphoractivated current in the presence of elevated temperatures was greater than the sum of the two agonists when applied alone and suggests that the effect of camphor is likely to be increased at physiological temperatures.

The activation of TRPV 1 can be further increased by proalgesic agents such as bradykinin and nerve growth factor, which are released after tissue injury or in irritated conditions (Chuang et al., 2001; Ji and Strichartz, 2004). Because camphor is known as an effective counterirritant (Burkhart and Burkhart, 2003) but only weakly generates warmth sensations when applied in isolation (Green, 1990), we asked whether the effect of camphor might be stronger under irritated and inflamed conditions when the 
activity of TRPV1 is enhanced. Both type 1 muscarinic receptor (M1) and type II bradykinin receptor (B2R) are known to couple to PLC via their activation of $\mathrm{G} \alpha \mathrm{q} / 11$. The resulting hydrolysis of phosphatidylinositol-4,5-bisphosphate $\left(\mathrm{PIP}_{2}\right)$ and the activation of protein kinase $\mathrm{C}(\mathrm{PKC})$ are likely to combine to sensitize TRPV1 (Premkumar and Ahern, 2000; Chuang et al., 2001; Numazaki et al., 2002; Bhave et al., 2003). We tested whether stimulation of PLC-coupled receptors enhances the ability of camphor to activate TRPV1 channels. In HM1 cells expressing rTRPV1, the application of $1.5 \mathrm{~mm}$ camphor slightly increased the rTRPV1-specific basal current (Fig. 9C-E). However, addition of the muscarinic agonist carbachol at $20 \mu \mathrm{M}$, in the continued presence of $1.5 \mathrm{~mm}$ camphor, greatly enhanced $I_{\text {rTRPV1 }}$. The outward current (measured at $+60 \mathrm{mV}$ ) increased $\sim 10$-fold from $22 \pm 8 \mathrm{pA} / \mathrm{pF}$ to $207 \pm 37 \mathrm{pA} / \mathrm{pF}(n=5)$. The inward current $(-60 \mathrm{mV})$ also increased approximately eightfold from $-3.3 \pm 0.8 \mathrm{pA} / \mathrm{pF}$ to $-26 \pm 10 \mathrm{pA} / \mathrm{pF}(n=5)$. The applications of $20 \mu \mathrm{M}$ carbachol alone usually only increased outward currents slightly but had no effect on inward currents (data not shown). Bradykinin $(1 \mu \mathrm{M})$ had similar sensitizing effects on camphorinduced currents in cells cotransfected with rTRPV1 and B2R ( $n=2$; data not shown). Together, these results suggest that the camphor-induced TRPV1-mediated response can be enhanced by PLC-coupled receptor stimulation, and this enhancement may increase the effectiveness of camphor in conditions in which TRPV1 is already sensitized. Enhanced camphor activation of TRPV1 is likely to lead to enhanced desensitization, perhaps making camphor a more effective counterirritant under inflamed conditions.

\section{Camphor activation of TRPV1-like currents in DRG sensory neurons}

Because camphor robustly activates TRPV1 channels heterologously expressed in HEK cells, the in vivo sensitization to warm stimuli caused by camphor application (Green, 1990) may result from the activation of TRPV1 expressed in sensory neurons. To determine whether camphor is able to activate native TRPV1containing channels, we recorded from acutely dissociated rat DRG neurons using solutions designed to minimize the contribution of the large voltage-gated currents present in these neurons (Blair and Bean, 2002). Internal $\mathrm{Cs}^{+}$and external $\mathrm{Cs}^{+}$and TEA (in some experiments) were included to reduce $\mathrm{K}^{+}$currents, $\mathrm{Cd}^{2+}$ or a mixture of blockers to reduce voltage-gated $\mathrm{Ca}^{2+}$ currents, and TTX to block TTX-sensitive sodium current. Inward currents from -100 to approximately $-20 \mathrm{mV}$ were quite small (less than $-10 \mathrm{pA}$ total) and stable in these conditions (Fig. 10A). As the ramp voltage continued, an inward current began to activate, peaking at approximately $-10 \mathrm{mV}$. This current is likely the result of TTX-resistant (TTX-R) sodium channels expressed in many nociceptive neurons, because it was strongly use dependent (Blair and Bean, 2003) and was inhibited after $1 \mu \mathrm{M}$ capsaicin application (Liu et al., 2001). Residual outward currents during the ramp were generally large, yet also declined and reached a steady state after 10-15 voltage ramps.

Camphor was added to the DRG neuron shown in Figure $10 \mathrm{~B}$ at 1,3 , and $10 \mathrm{~mm}$. One and $3 \mathrm{~mm}$ camphor both activated a small outward current during voltage ramps, with $5.5 \mathrm{pA} / \mathrm{pF}$ net current density at $+80 \mathrm{mV}$ activated by $1 \mathrm{~mm}$ camphor and 9.8 $\mathrm{pA} / \mathrm{pF}$ net current density activated by $3 \mathrm{~mm}$ camphor. Little or no inward current was activated by these camphor concentrations. Although TRPV1 channels are nonselective cation channels, which pass inward and outward currents, the activation of TRPV1 by heat and agonists appears to act by shifting the voltage
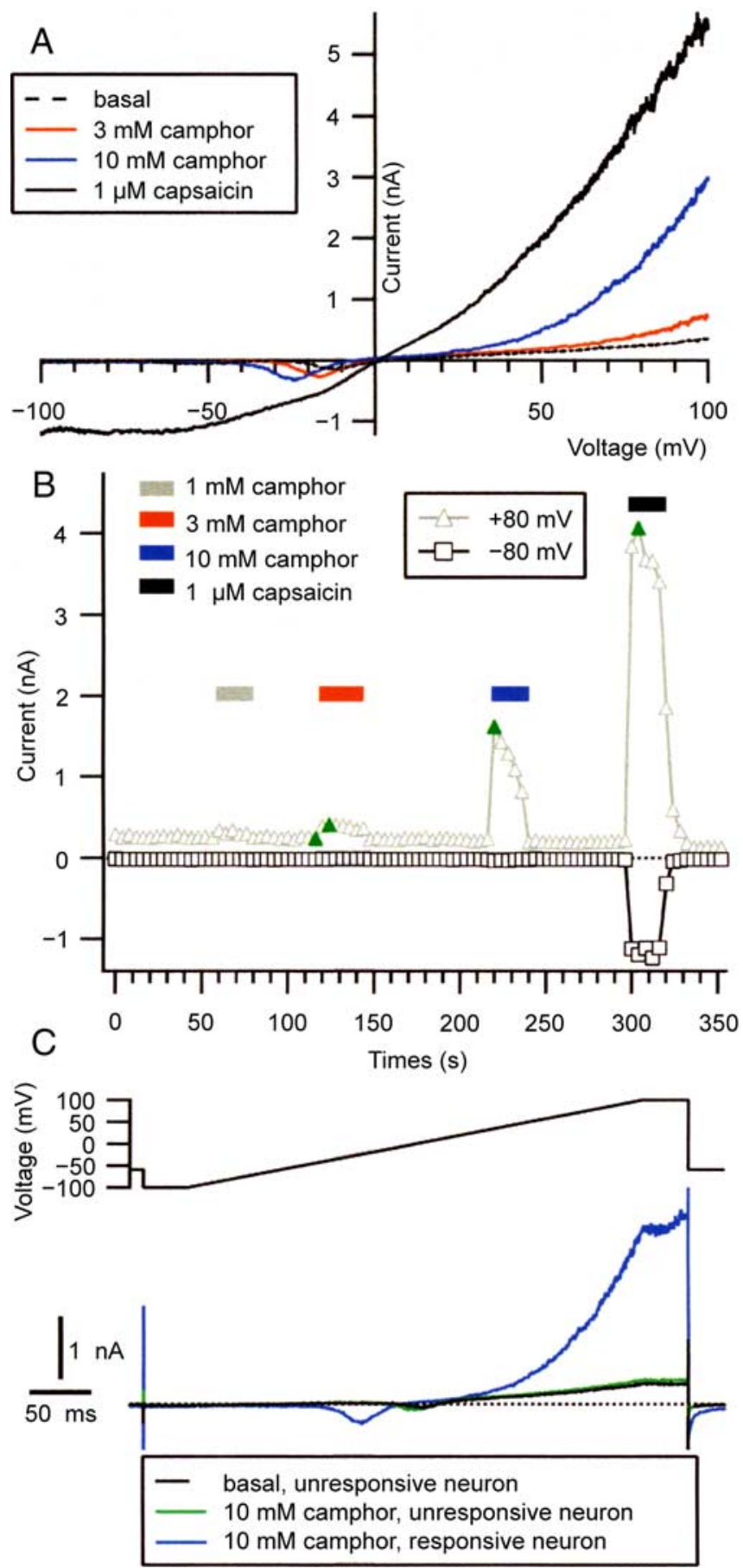

Figure 10. Camphor activates a TRPV1-like current in DRG neurons. $\boldsymbol{A}$, Currents evoked by voltage ramps ( $400 \mathrm{~ms}$; from -100 to $+100 \mathrm{mV}$ ) are shown in basal conditions (dashed line), in the presence of $3 \mathrm{~mm}$ (red line) and $10 \mathrm{~mm}$ (blue line) camphor, and during application of $1 \mu \mathrm{m}$ capsaicin (solid black line). The holding potential between ramps was $-60 \mathrm{mV}$. B, Increasing concentrations of camphor (applied during bars) elicited increasing amounts of current in a DRG neuron. The current at $+80 \mathrm{mV}$ (triangles) and $-80 \mathrm{mV}$ (squares) during the ramps are shown. The positions of the ramp currents plotted in $\boldsymbol{A}$ are indicated by the green symbols; the dotted line indicates zero current level. $\boldsymbol{C}$, Currents in the presence of $10 \mathrm{~mm}$ camphor recorded from a camphor-unresponsive neuron (green line) and from the same camphor-responsive neuron shown in $\boldsymbol{A}$ for comparison. The entire voltage protocol is shown, including the $40 \mathrm{~ms}$ at -100 and $+100 \mathrm{mV}$ flanking the ramp. The black dashed line shows the basal current recorded in the camphor-unresponsive neuron, which happened to have similar amplitude to the camphorresponsive cell. 
dependence of the channel to more hyperpolarized potentials (Voets et al., 2004). These low concentrations of camphor may shift the $G-V$ curve less than saturating doses of capsaicin, leading to activation predominantly at positive potentials.

Application of $10 \mathrm{~mm}$ camphor elicited a large outward current that peaked at a net current density of $86.8 \mathrm{pA} / \mathrm{pF}$ at $+80 \mathrm{mV}$ and also activated a small but resolvable inward current, which reached $-0.9 \mathrm{pA} / \mathrm{pF}$ net current density at $-80 \mathrm{mV}$. In contrast to the currents elicited by 1 and $3 \mathrm{~mm}$ camphor, which were stable in amplitude throughout the camphor application, the current elicited by $10 \mathrm{~mm}$ camphor declined by $58 \%$ (from 86.8 to 36.8 $\mathrm{pA} / \mathrm{pF}$ ) over the $16 \mathrm{~s}$ after the peak. Addition of $1 \mu \mathrm{M}$ capsaicin to this DRG neuron activated a large inward and outward current that reversed near $0 \mathrm{mV}$, with $239 \mathrm{pA} / \mathrm{pF}$ at $+80 \mathrm{mV}$ and -76 $\mathrm{pA} / \mathrm{pF}$ at $-80 \mathrm{mV}$. Thus, as was the case with heterologously expressed TRPV1, capsaicin appears to be a much stronger agonist than camphor for the native current response.

A total of 25 DRG neurons were tested with both $10 \mathrm{~mm}$ camphor and $1 \mu \mathrm{M}$ capsaicin. We focused on DRG neurons that were likely nociceptors, choosing small-diameter $(24.6 \pm 1.3 \mathrm{pF}$; $n=27$ ) neurons with TTX-R sodium currents. Although $10 \mathrm{~mm}$ camphor led to net increases in current in 25 of 27 small DRG neurons (with net block in the two remaining neurons), we considered 12 of these 25 cells to be camphor-responsive under naive conditions. The camphor-activated current in these cells was similar to that shown in Figure $10 \mathrm{~A}$, increasing throughout the depolarizing portion of the voltage ramp and further increasing during the $40 \mathrm{~ms}$ at $+100 \mathrm{mV}$ after the ramp (Fig. 10C). Camphor-elicited $(10 \mathrm{~mm})$ currents from these cells were $>5$ $\mathrm{pA} / \mathrm{pF}$ net density at $+80 \mathrm{mV}$; in contrast, those neurons with net current densities of $<5 \mathrm{pA} / \mathrm{pF}$ at $+80 \mathrm{mV}$ in $10 \mathrm{~mm}$ camphor had a more constant current amplitude throughout the depolarizing voltage range and a constant current during the $40 \mathrm{~ms}$ step at $+100 \mathrm{mV}$ (which we do not consider camphor responsive under naive conditions) (Fig. 10C). The camphor-elicited current during ramps was consistently larger at positive potentials compared with negative potentials. The average $+80 \mathrm{mV}$ net current density for these neurons was $26.2 \pm 7.0 \mathrm{pA} / \mathrm{pF}(n=12)$, whereas the net inward current at $-80 \mathrm{mV}$ was small or nearly zero (average, $-0.4 \pm 0.1 \mathrm{pA} / \mathrm{pF}$ ). Application of 1 and $3 \mathrm{~mm}$ camphor to three camphor-responsive neurons elicited smaller TRPV1-like currents: $>5 \mathrm{pA} / \mathrm{pF}$ net current density was elicited in one of three neurons in response to $1 \mathrm{~mm}$ camphor and two of three neurons in response to $3 \mathrm{~mm}$. The small or absent inward currents elicited by camphor in DRG neurons is similar to results reported by Moqrich et al. (2005).

Eleven of the 12 camphor-responsive DRG neurons also had large currents activated by the application of $1 \mu \mathrm{M}$ capsaicin. Capsaicin currents were, in general, much larger than currents in response to $10 \mathrm{~mm}$ camphor: average net current density at +80 $\mathrm{mV}$ for all camphor-responsive cells was $258.1 \pm 73.9 \mathrm{pA} / \mathrm{pF}$ $(n=11)$. Capsaicin also elicited substantial inward current. Comparing the amplitude of the camphor response relative to the capsaicin response in each individual neuron, camphor current was between 5.8 and $71 \%(+80 \mathrm{mV})$ of the $1 \mu \mathrm{M}$ capsaicin current. The lone camphor-responsive neuron that lacked capsaicinactivated current might have been the result of camphormediated desensitization of TRPV1 or may have expressed capsaicin-insensitive TRPV1 splice variants (Lu et al., 2005) or alternatively the presence of TRPV3 channels.

The TRPV1-like ramp current activated by $10 \mathrm{~mm}$ camphor in DRG neurons typically reached steady state within the $4 \mathrm{~s}$ interval separating sweeps and did not decline during the $20 \mathrm{~s}$ exposure to camphor ( 6 of 12 camphor-responsive cells). In the six remaining cells, including the cell shown in Figure 10, application of $10 \mathrm{~mm}$ camphor initially led to the activation of a large camphor current, which then declined over the subsequent 16 s to $42 \%$ of the initial peak. Interestingly, the strong desensitization of the camphoractivated current in these cells occurred in the absence of large net inward current, which has been suggested to correlate with desensitization of the capsaicin response (Bhave et al., 2002), suggesting that camphor might recruit additional desensitization mechanisms. Indeed, the current activated by a subsequent application of $1 \mu \mathrm{M}$ capsaicin in the same cell did not desensitize to the same degree, despite the much larger inward current amplitude (Fig. 10A, B). This desensitization of the current elicited by $10 \mathrm{~mm}$ camphor in DRG neurons was broadly similar to that recorded from TRPV1-expressing HEK cells (Figs. 7, 8). The processes underlying this differential desensitization in camphor relative to capsaicin are unclear (see Discussion). The $10 \mathrm{~mm}$ camphor-activated current in six of these cells was steady throughout the $20 \mathrm{~s}$ application typically used, whereas in the six other cells, the camphor current initially reached a peak $\sim 4 \mathrm{~s}$ after camphor application, followed by a decline in the current of $46 \pm$ $8 \%$. The DRG neurons that had desensitizing camphor-activated currents tended to be those cells with the largest peak camphor currents, with an average of $39.6 \pm 11.6 \mathrm{pA} / \mathrm{pF}$ versus $12.8 \pm 3.2$ $\mathrm{pA} / \mathrm{pF}$ in those nondesensitizing cells.

The remaining 13 capsaicin-responsive cells had net $10 \mathrm{~mm}$ camphor current densities at $+80 \mathrm{mV}$ of $<5 \mathrm{pA} / \mathrm{pF}$. These cells typically had much smaller capsaicin currents than the $12 \mathrm{DRG}$ cells in which camphor alone activated significant current during voltage ramps. The average net current density at $+80 \mathrm{mV}$ activated by $1 \mu \mathrm{M}$ capsaicin in these 13 cells was $32.9 \pm 17.4 \mathrm{pA} / \mathrm{pF}$, whereas the 12 camphor-responsive cells had an average current density of $258.1 \pm 73.9 \mathrm{pA} / \mathrm{pF}$. Possibly, the absence of camphoractivated currents in these cells was a result of the lower level of TRPV1 expression, and any small currents activated by the weaker agonist camphor were not resolvable. Although the net current in these cells may contain some contribution of TRPV1 channels, it is possible that other currents were affected by camphor in these cells to generate small increases in outward ramp currents.

Camphor also routinely shifted the voltage of the peak inward current contributed by TTX-resistant sodium channels to more hyperpolarized potentials. As shown in Figure $10 \mathrm{~A}$, application of 3 and $10 \mathrm{~mm}$ camphor shifted the inward current peak $\sim 5-10$ $\mathrm{mV}$ more negative; $1 \mathrm{~mm}$ camphor had a much smaller effect. This was a consistent finding among DRG neurons, even in those in which the net camphor elicited current density at $+80 \mathrm{mV}$ was $<5 \mathrm{pA} / \mathrm{pF}$ (Fig. 10c). Application of the vehicle DMSO at $0.5 \%$, the concentration in solutions with $10 \mathrm{~mm}$ camphor, did not cause a similar shift in TTX-resistant sodium current. The mechanism of this shift in the voltage dependence of TTX-resistant sodium current is not clear, although it is potentially an important contributor to the effect of camphor. The TTX-R sodium current is important in DRG neuron firing properties, and the hyperpolarizing shift in camphor might cause the neuron to respond to previously subthreshold stimuli, which could lead to enhanced desensitization (Blair and Bean, 2003).

\section{Camphor-activated currents in DRG neurons are potentiated by PMA treatment}

Although the camphor-activated currents recorded in many DRG neurons resembled responses from HEK cells heterolo- 
A

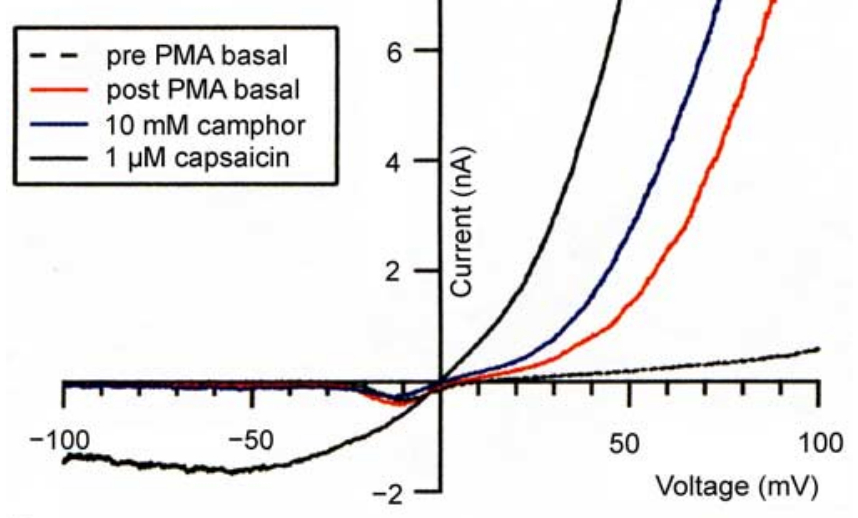

B

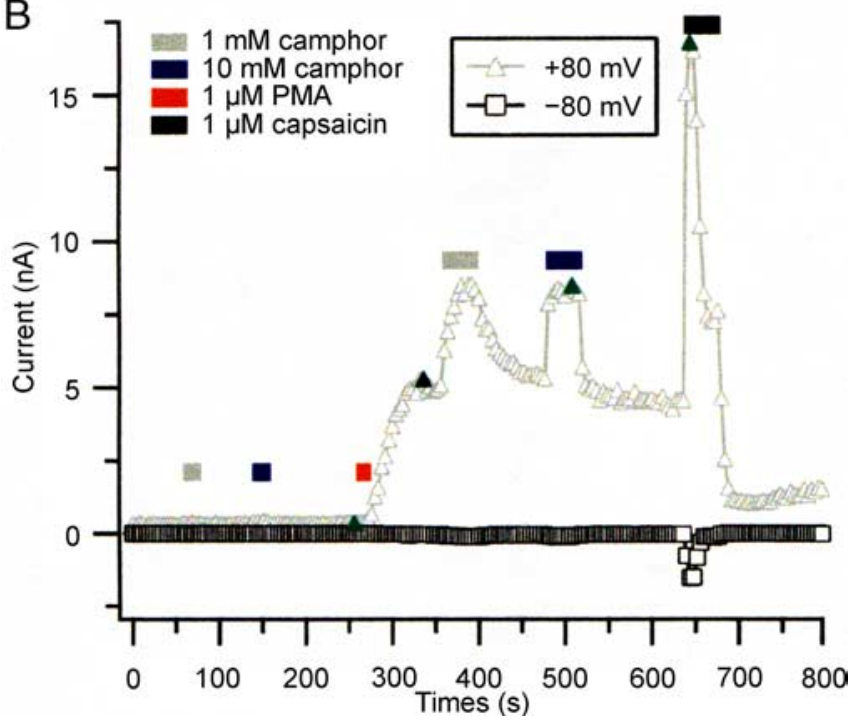

Figure 11. PMA treatment enhances camphor-activated currents in DRG neurons. $A$, Ramp currents from -100 to $+100 \mathrm{mV}$ at baseline before PMA addition (dashed line) and after a $16 \mathrm{~s}$ application of $1 \mu \mathrm{m}$ PMA application (red line). The application of $10 \mathrm{~mm}$ camphor (blue line) and $1 \mu \mathrm{m}$ capsaicin (solid black line) after PMA treatment elicited large ramp currents similar to heterologously expressed TRPV1. B, The current at $+80 \mathrm{mV}$ (triangles) and $-80 \mathrm{mV}$ (squares) during voltage ramps in the cell in $A$ is plotted. The positions of the ramp currents displayed in $A$ are indicated by the green symbols. The dotted line indicates zero current level.

gously expressing TRPV1, DRG neurons may express numerous channels that are potentially sensitive to camphor. TRPV1 channel activity is enhanced by treatment with the PKC activator PMA (Premkumar and Ahern, 2000; Vellani et al., 2001; Bhave et al., 2003). If camphor-activated currents in DRG neurons are mediated by TRPV1, then PMA would be expected to enhance the effect of camphor. Furthermore, PKC stimulation has been shown to be an important mediator during inflammatory conditions (Bhave and Gereau, 2004; Ji and Strichartz, 2004), potentially explaining the use of camphor in inflamed states.

To determine whether the ability of camphor to activate TRPV1-like current in DRG neurons was enhanced after PKC stimulation, we compared the responses of DRG neurons to camphor application before and after a 20-40 s exposure to $1 \mu \mathrm{M}$ PMA. As shown in Figure $11 A$, the camphor-activated current was small in the naive state, with $0.9 \mathrm{pA} / \mathrm{pF}$ net current density at $+80 \mathrm{mV}$ elicited by $1 \mathrm{~mm}$ camphor and $5.1 \mathrm{pA} / \mathrm{pF}$ elicited by 10 mM camphor. The neuron was then treated with $1 \mu \mathrm{M}$ PMA for $16 \mathrm{~s}$. At this time, a current quite similar to TRPV1 began to activate, increasing to $224.9 \mathrm{pA} / \mathrm{pF}$ net $+80 \mathrm{mV}$ current density and $-1.5 \mathrm{pA} / \mathrm{pF}$ at $-80 \mathrm{mV}$ over the subsequent $\sim 60 \mathrm{~s}$, despite the return of the cell to control external solutions. This PMA activation of TRPV1 current in DRGs is likely to result from both modulation of TRPV1 channels attributable to PKC phosphorylation (Premkumar and Ahern, 2000; Numazaki et al., 2002; Bhave et al., 2003) and from a direct binding of PMA to activate TRPV1 (Chuang et al., 2001; Bhave et al., 2003).

When camphor was added to this neuron after PMA treatment, a much larger TRPV1-like current was elicited (Fig. $11 A, B)$. The $+80 \mathrm{mV}$ net current density (relative to the larger post-PMA basal current) in $1 \mathrm{~mm}$ camphor was $94.1 \mathrm{pA} / \mathrm{pF}$, and the $-80 \mathrm{mV}$ net current density was further increased by -1.0 $\mathrm{pA} / \mathrm{pF}$. The $10 \mathrm{~mm}$ camphor-elicited current was increased to $151.3 \mathrm{pA} / \mathrm{pF}$ at $+80 \mathrm{mV}$ and $-2.8 \mathrm{pA} / \mathrm{pF}$ at $-80 \mathrm{mV}$. The onset of the $1 \mathrm{~mm}$ camphor current was slower than the $10 \mathrm{~mm}$ camphor application, presumably reflecting a decreased association rate with the putative TRPV1 camphor-binding site.

Application of $1 \mu \mathrm{M}$ capsaicin to the PMA-treated neuron resulted in a very large current activation, followed by substantial desensitization even during relatively short capsaicin applications. Such strong desensitization during capsaicin application was not typically seen in non-PMA-treated neurons with the solutions used here. After the removal of capsaicin, the current then declined to a lower amplitude than the previous post-PMA basal level. Slowly, the basal current began to increase, eventually reaching the level before capsaicin treatment. Application of 10 $\mathrm{mM}$ camphor during this postcapsaicin recovery resulted in current activation with a smaller amplitude than previously (127.9 $\mathrm{pA} / \mathrm{pF}$ and $-1.3 \mathrm{pA} / \mathrm{pF}$ at $-80 \mathrm{mV}$ ). The decrease and subsequent slow recovery of the basal TRPV1-like current may result from the hydrolysis and resynthesis of membrane $\mathrm{PIP}_{2}$, as shown by Liu et al. (2005).

Fourteen DRG neurons were treated with $1 \mu \mathrm{M}$ PMA, typically for $20 \mathrm{~s}$ (range, $16-40 \mathrm{~s}$ ). In 9 of these 13 cells, PMA alone elicited currents of 20.7-224.9 pA/pF at $+80 \mathrm{mV}$. The PMA-elicited current generally began to rise 12-40 s after the onset of the PMA exposure, increasing the basal current to a new steady-state value during the next 80-200 s. This effect persisted for the remainder of the 10-15 min experiment, despite the limited duration of the PMA exposure. The remaining 4 of 13 cells had post-PMA increases in a current of $\sim 4 \mathrm{pA} / \mathrm{pF}$ or less. These four cells were considered to be unresponsive to PMA and were either not capsaicin responsive or had very small currents in response to $1 \mu \mathrm{M}$ capsaicin (approximately $-1 \mathrm{pA} / \mathrm{pF}$ net capsaicin-elicited current at $-80 \mathrm{mV}$ ). These cells presumably expressed only very low levels of TRPV1.

PMA treatment of DRG neurons strongly enhanced the current activated by camphor. Eight of the nine PMA-responsive cells had $10 \mathrm{~mm}$ camphor-activated currents of $<5 \mathrm{pA} / \mathrm{pF}$ in the naive state and would not have been included in camphorresponsive cells as described above. Yet after PMA treatment, 10 $\mathrm{mM}$ camphor activated currents at $+80 \mathrm{mV}$ with a net current density ranging from 22.3 to $151.32 \mathrm{pA} / \mathrm{pF}$ (average, $54.1 \pm 14.1$ $\mathrm{pA} / \mathrm{pF} ; n=9)$. Furthermore, in six of these nine cells, $10 \mathrm{~mm}$ camphor was able to activate a small net inward current, which was not resolvable before PMA modulation $(-0.6$ to $-2.1 \mathrm{pA} / \mathrm{pF}$ at $-80 \mathrm{mV})$.

Not only did PMA treatment lead to inward current generated by the application of $10 \mathrm{~mm}$ camphor, it also led to appreciable responses of TRPV1-like current in response to a lower concentration of $1 \mathrm{~mm}$ camphor. In four DRG neurons treated with both 1 and $10 \mathrm{~mm}$ camphor after treatment with $1 \mu \mathrm{M}$ PMA, $1 \mathrm{mM}$ 
camphor elicited current larger in three of four cells $(5,14$, and $75 \%$ larger; $11 \%$ smaller), although as in Figure $11 A$, the $1 \mathrm{~mm}$ camphor-activated current required a longer duration to reach steady state. The larger current in response to $1 \mathrm{~mm}$ camphor might be the result of reduced direct block of TRPV1 channels in DRG neurons as observed in heterologous expression (Fig. $6 A, B)$. The resulting net current activated by $1 \mathrm{~mm}$ camphor might be larger if PMA shifts the dose-response for activation to a point where 1 and $10 \mathrm{mM}$ camphor are able to activate TRPV1 to a similar extent.

\section{Discussion}

Although camphor-containing balms are available over the counter for their topical analgesic and counterirritant actions, the underlying molecular and neuronal mechanisms are not known. We found that camphor activates and desensitizes the capsaicin receptor (TRPV1) while inhibiting the TRPA1 channel, both of which are heavily expressed in nociceptive sensory neurons. Our results not only present a novel modulation of TRPV1 channel but also provide a molecular connection between camphor, thermosensation, and nociception.

\section{Activation mechanisms of camphor on TRPV1}

The precise mechanism by which camphor activates TRPV1 is not clear. Camphor may directly bind to TRPV1 and promote channel opening in a mechanism analogous to capsaicin activation (Jordt and Julius, 2002). Alternatively, camphor could initiate an endogenous signaling pathway to generate substances that activate TRPV1, such as anandamide (Zygmunt et al., 1999) or 12-hydroxyeicosatetraenoic acid (Hwang et al., 2000). For several reasons, we favor the former possibility. First, the kinetics of TRPV1 activation in response to camphor application is rapid, occurring on the timescale of solution addition, similar to capsaicin activation in the same cells. Second, camphor was unable to activate the chicken ortholog of TRPV1, which is $68 \%$ identical to the rat, and remains sensitive to protons, heat, and, importantly, PLC-coupled receptor stimulation (Jordt and Julius, 2002). Third, many endogenous activators, including anandamide, act at the vanilloid binding site, yet we found that camphor activation of TRPV1 was preserved in cases in which vanilloiddependent activation was abolished by mutation or capsazepine. Although direct binding and activation of TRPV1 by camphor appears to be a likely mechanism, we cannot rule out the possibility that alteration of endogenous signaling pathways may play a role on the effect of camphor on TRPV1.

The location of the putative camphor-binding site on TRPV1 is not clear. The inability of camphor to activate chicken TRPV1 or the crcTRPV1 (Fig. 6) suggests that the binding site lies outside of the transmembrane 2-4 region. Examination of shared sequences between TRPV3 and rTRPV1, which are both camphor sensitive, and comparison with the camphor insensitive cTRPV1, TRPV2, and TRPV4 may yield important clues to localize molecular determinants required for camphor action.

\section{Efficacy and potency of camphor}

Although camphor robustly activates TRPV1, the maximal current induced by $10 \mathrm{~mm}$ camphor was still smaller than the current activated by $1 \mu \mathrm{M}$ capsaicin or $\mathrm{pH} 4.2$ solution (Figs. 2, 8). The camphor-activated TRPV1-like currents were also quite small in naive DRG neurons related to capsaicin-elicited currents (Fig. 10 ), which is possibly related to the larger $\mathrm{EC}_{50}$ value of capsaicinactivated current in DRG neurons (Oh et al., 1996; Koplas et al., 1997; Shin et al., 2001; Vellani et al., 2001) relative to heterolo- gously expressed TRPV1 (Tominaga et al., 1998; Gunthorpe et al., 2000; Shin et al., 2001; Mohapatra et al., 2003). Larger TRPV1 currents might have been recorded if we were able to use higher camphor concentrations that were precluded because of low solubility. Therefore, we suggest that for TRPV1, camphor has both low intrinsic efficacy and potency in our experimental conditions, in some ways resembling that of anandamide (Ross, 2003) and NADA (Premkumar et al., 2004).

Despite the high absolute camphor concentrations required for TRPV1 activation, this activation seems likely to contribute to the analgesic and counterirritant properties of camphor. Although the concentration of topically applied camphor present at DRG sensory neuron endings in the skin is unknown, the relative concentration of camphor in balms is similar to that in capsaicin and menthol used topically for similar purposes. Camphorcontaining balms typically are prepared at 3-10\%, which corresponds to $\sim 200-600 \mathrm{~mm}$. In comparison, capsaicin creams contain $0.025 \%(\sim 800 \mu \mathrm{M})$ and menthol-containing preparations contain 1-10\% (100-600 mM). Furthermore, menthol activation of the TRPM8 channel requires millimolar range for full activation, and at near physiological temperatures $\left(>30^{\circ} \mathrm{C}\right)$ even this high-menthol concentration results in incomplete activation (McKemy et al., 2002; Peier et al., 2002a).

Because TRPV1 is a polymodal receptor, the low intrinsic efficacy of camphor on TRPV1 might also be tuned by other factors. Indeed, the currents induced by $3 \mathrm{~mm}$ camphor were significantly larger when the temperature was elevated to a more physiologically relevant range (Fig. 9). Stimulation of PLCcoupled receptors produced a similar enhancement of the activation of TRPV1 by camphor, presumably by shifting the camphor dose-response curve. Conceivably, in irritated or inflamed states, camphor could activate TRPV1 more effectively than under naive conditions because of the multiple sensitization mechanisms that enhance TRPV1 activity in sensory neurons (Ji and Strichartz, 2004). For example, increased PKC activity is an important peripheral sensitization mechanism (for review, see Bhave and Gereau, 2004; Ji and Strichartz, 2004). PKC-mediated phosphorylation of TRPV1 can enhance TRPV1 activity both through shifts in agonist potency and reductions in desensitization (Bhave and Gereau, 2004; Ji and Strichartz, 2004). We found that activation of PKC by PMA treatment in DRG neurons strongly enhanced the ability of camphor to activate TRPV1-like currents. PMA treatment also rendered DRG neurons responsive to previously ineffective concentrations of camphor (Fig. 11). Most effective topical analgesics, including capsaicin and menthol, cause a strong sensation of irritation (i.e., burning, stinging, and itching) when applied to the skin in the resting conditions (Green, 1990), an effect consistent with the high efficacy of capsaicin and menthol on TRPV1 and TRPM8, respectively. In contrast, camphor application to the skin produces a slight "burning" sensation at warm temperatures, which does not reach painful levels (Green, 1990), likely related to the low intrinsic efficacy of camphor. Thus, the effective use of camphor as a counterirritant to treat irritated and inflamed skin (Green, 1990; Burkhart and Burkhart, 2003) may be related to the increased efficacy of camphor in these states.

\section{Strong desensitization mechanisms of TRPV1 and implication for topical analgesia}

Camphor-activated TRPV1 currents exhibited strong acute desensitization and tachyphylaxis, which in most cases were stronger than the reduction after capsaicin treatment (Fig. 8). There is also likely to be an inhibitory action of camphor on rTRPV1, 
because camphor was effective at reducing low-pH solutionelicited currents in cells expressing chicken TRPV1 and the chicken-rat chimeric protein. This inhibition, presumably resulting from direct block of TRPV1 by camphor, might partially explain the low potency by leading to a reduction in net current activation at high-camphor concentrations. However, this inhibitory action was clearly distinct from desensitization and tachyphlyaxis as it quickly reversed after camphor removal. Therefore, camphor block of TRPV1 might contribute in part to the acute desensitization phase of camphor addition but is unlikely to contribute the long-lasting camphor-induced tachyphylaxis. Capsaicin-induced desensitization depends on both $\mathrm{Ca}^{2+}$ dependent and $\mathrm{Ca}^{2+}$-independent mechanisms (Koplas et al., 1997). Camphor-induced TRPV1 desensitization was robust after the removal of external $\mathrm{Ca}^{2+}$ (our unpublished data), suggesting a primary mechanism that is $\mathrm{Ca}^{2+}$ independent. The degree of desensitization appeared to be correlated with the amplitude of camphor-induced current. Because of the aforementioned low efficacy of camphor, the analgesic action of camphor might be only evident in irritated or diseased states (Menendez et al., 2004), in which camphor-activated currents and resulting desensitization are expected to be larger.

Capsaicin-induced TRPV1 channel desensitization has been proposed to mediate the capsaicin desensitization of nociceptive nerves (Koplas et al., 1997; Bhave et al., 2002; Menendez et al., 2004; Szolcsanyi, 2004). Because camphor desensitizes TRPV1 even more strongly than capsaicin, we propose that camphorinduced desensitization of TRPV1 contribute to the analgesic and counterirritant actions of camphor. In fact, the small inward currents activated by camphor suggest that, in the presence of a sufficient camphor concentration, significant pain relief might be attained without the initial painful experience that accompanies the application of topical capsaicin treatments. As a comparison, TRPV3 currents sensitize after repeated stimulations. Therefore, although TRPV3 may mediate the psychophysical effects of camphor (Moqrich et al., 2005), it appears unlikely to play a role in analgesia.

\section{Inhibition on TRPA1 channel and implication for topical analgesia}

TRPA1 was originally described as a channel activated by noxious cold (Story et al., 2003), yet activation of TRPA1 by cold remains uncertain (Jordt et al., 2004; Nagata et al., 2005). TRPA1, which is expressed in a large fraction of nociceptors, is activated by pungent compounds such as mustard oil and cinnamon oil and is activated by PLC-coupled receptor stimulation (Bandell et al., 2004; Jordt et al., 2004; Nagata et al., 2005). We found that camphor strongly inhibited the basal current of TRPA1 (Fig. 4). Although the role of TRPA1 in nociceptors is not clear, this inhibition might provide an additional target for the analgesic actions of camphor. Because such inhibition was also seen in several other sensory TRP channels (Fig. 3), the functional significance of TRPA1 inhibition might require experiments in mice with deletions of TRPA1 and TRPV1 genes.

\section{Concluding remarks}

We have shown that camphor selectively activates mammalian but not avian TRPV1. The activation of TRPV1 by camphor appears to occur via a novel mechanism, distinct from activation by vanilloids. Among TRPV1 agonists, camphor is unique in its strong desensitizing properties, which we propose account for, at least partially, the analgesic actions of camphor. In addition, the inhibitory effect of camphor on TRPA1 might also contribute to an antinociceptive role of camphor.

\section{References}

Ahern GP, Premkumar LS (2002) Voltage-dependent priming of rat vanilloid receptor: effects of agonist and protein kinase $\mathrm{C}$ activation. J Physiol (Lond) 545:441-451.

Bandell M, Story GM, Hwang SW, Viswanath V, Eid SR, Petrus MJ, Earley TJ, Patapoutian A (2004) Noxious cold ion channel TRPA1 is activated by pungent compounds and bradykinin. Neuron 41:849-857.

Bhave G, Gereau RW (2004) Posttranslational mechanisms of peripheral sensitization. J Neurobiol 61:88-106.

Bhave G, Zhu W, Wang H, Brasier DJ, Oxford GS, Gereau RW (2002) cAMP-dependent protein kinase regulates desensitization of the capsaicin receptor (VR1) by direct phosphorylation. Neuron 35:721-731.

Bhave G, Hu HJ, Glauner KS, Zhu W, Wang H, Brasier DJ, Oxford GS, Gereau RW (2003) Protein kinase C phosphorylation sensitizes but does not activate the capsaicin receptor transient receptor potential vanilloid 1 (TRPV1). Proc Natl Acad Sci USA 100:12480-12485.

Blair NT, Bean BP (2002) Roles of tetrodotoxin (TTX)-sensitive $\mathrm{Na}^{+}$current, TTX-resistant $\mathrm{Na}^{+}$current, and $\mathrm{Ca}^{2+}$ current in the action potentials of nociceptive sensory neurons. J Neurosci 22:10277-10290.

Blair NT, Bean BP (2003) Role of tetrodotoxin-resistant $\mathrm{Na}^{+}$current slow inactivation in adaptation of action potential firing in small-diameter dorsal root ganglion neurons. J Neurosci 23:10338-10350.

Brauchi S, Orio P, Latorre R (2004) Clues to understanding cold sensation: thermodynamics and electrophysiological analysis of the cold receptor TRPM8. Proc Natl Acad Sci USA 101:15494-15499.

Burkhart CG, Burkhart HR (2003) Contact irritant dermatitis and antipruritic agents: the need to address the itch. J Drugs Dermatol 2:143-146.

Burrow A, Eccles R, Jones AS (1983) The effects of camphor, eucalyptus and menthol vapour on nasal resistance to airflow and nasal sensation. Acta Otolaryngol 96:157-161.

Caterina MJ, Schumacher MA, Tominaga M, Rosen TA, Levine JD, Julius D (1997) The capsaicin receptor: a heat-activated ion channel in the pain pathway. Nature 389:816-824.

Chuang HH, Prescott ED, Kong H, Shields S, Jordt SE, Basbaum AI, Chao MV, Julius D (2001) Bradykinin and nerve growth factor release the capsaicin receptor from PtdIns(4,5)P2-mediated inhibition. Nature 411:957-962.

Chung MK, Lee H, Mizuno A, Suzuki M, Caterina MJ (2004) 2 -aminoethoxydiphenyl borate activates and sensitizes the heat-gated ion channel TRPV3. J Neurosci 24:5177-5182.

Chung MK, Guler AD, Caterina MJ (2005) Biphasic currents evoked by chemical or thermal activation of the heat-gated ion channel, TRPV3. J Biol Chem 280:15928-15941.

Clapham DE (2003) TRP channels as cellular sensors. Nature 426:517-524.

Garcia-Martinez C, Morenilla-Palao C, Planells-Cases R, Merino JM, FerrerMontiel A (2000) Identification of an aspartic residue in the P-loop of the vanilloid receptor that modulates pore properties. J Biol Chem 275:32552-32558.

Green BG (1990) Sensory characteristics of camphor. J Invest Dermatol 94:662-666.

Gunthorpe MJ, Harries MH, Prinjha RK, Davis JB, Randall A (2000) Voltage- and time-dependent properties of the recombinant rat vanilloid receptor (rVR1). J Physiol (Lond) 525:747-759.

Hu HZ, Gu Q, Wang C, Colton CK, Tang J, Kinoshita-Kawada M, Lee LY, Wood JD, Zhu MX (2004) 2-aminoethoxydiphenyl borate is a common activator of TRPV1, TRPV2, and TRPV3. J Biol Chem 279:35741-35748.

Hwang SW, Cho H, Kwak J, Lee SY, Kang CJ, Jung J, Cho S, Min KH, Suh YG, Kim D, Oh U (2000) Direct activation of capsaicin receptors by products of lipoxygenases: endogenous capsaicin-like substances. Proc Natl Acad Sci USA 97:6155-6160.

Jancso N, Jancso-Gabor A, Szolcsanyi J (1967) Direct evidence for neurogenic inflammation and its prevention by denervation and by pretreatment with capsaicin. Br J Pharmacol 31:138-151.

Ji RR, Strichartz G (2004) Cell signaling and the genesis of neuropathic pain. Sci STKE 252:reE14.

Jordt SE, Julius D (2002) Molecular basis for species-specific sensitivity to "hot" chili peppers. Cell 108:421-430.

Jordt SE, Tominaga M, Julius D (2000) Acid potentiation of the capsaicin 
receptor determined by a key extracellular site. Proc Natl Acad Sci USA 97:8134-8139.

Jordt SE, McKemy DD, Julius D (2003) Lessons from peppers and peppermint: the molecular logic of thermosensation. Curr Opin Neurobiol 13:487-492.

Jordt SE, Bautista DM, Chuang HH, McKemy DD, Zygmunt PM, Hogestatt ED, Meng ID, Julius D (2004) Mustard oils and cannabinoids excite sensory nerve fibres through the TRP channel ANKTM1. Nature 427:260-265.

Koplas PA, Rosenberg RL, Oxford GS (1997) The role of calcium in the desensitization of capsaicin responses in rat dorsal root ganglion neurons. J Neurosci 17:3525-3537.

Liu B, Zhang C, Qin F (2005) Functional recovery from desensitization of vanilloid receptor TRPV1 requires resynthesis of phosphatidylinositol 4,5-bisphosphate. J Neurosci 25:4835-4843.

Liu L, Oortgiesen M, Li L, Simon SA (2001) Capsaicin inhibits activation of voltage-gated sodium currents in capsaicin-sensitive trigeminal ganglion neurons. J Neurophysiol 85:745-758.

Lu G, Henderson D, Liu L, Reinhart PH, Simon SA (2005) TRPV1b, a functional human vanilloid receptor splice variant. Mol Pharmacol 67:1119-1127.

McKemy DD, Neuhausser WM, Julius D (2002) Identification of a cold receptor reveals a general role for TRP channels in thermosensation. Nature 416:52-58.

Menendez L, Lastra A, Hidalgo A, Baamonde A (2004) The analgesic effect induced by capsaicin is enhanced in inflammatory states. Life Sci 74:3235-3244.

Mohapatra DP, Wang SY, Wang GK, Nau C (2003) A tyrosine residue in TM6 of the vanilloid receptor TRPV1 involved in desensitization and calcium permeability of capsaicin-activated currents. Mol Cell Neurosci 23:314-324.

Montell C (2005) The TRP superfamily of cation channels. Sci STKE 272:re3.

Moqrich A, Hwang SW, Earley TJ, Petrus MJ, Murray AN, Spencer KS, Andahazy M, Story GM, Patapoutian A (2005) Impaired thermosensation in mice lacking TRPV3, a heat and camphor sensor in the skin. Science 307:1468-1472.

Nagata K, Duggan A, Kumar G, Garcia-Anoveros J (2005) Nociceptor and hair cell transducer properties of TRPA1, a channel for pain and hearing. J Neurosci 25:4052-4061.

Neher E (1992) Correction for liquid junction potentials in patch clamp experiments. Methods Enzymol 207:123-131.

Numazaki M, Tominaga T, Toyooka H, Tominaga M (2002) Direct phosphorylation of capsaicin receptor VR1 by protein kinase C epsilon and identification of two target serine residues. J Biol Chem 277:13375-13378.

Oh U, Hwang SW, Kim D (1996) Capsaicin activates a nonselective cation channel in cultured neonatal rat dorsal root ganglion neurons. J Neurosci 16:1659-1667.

Patapoutian A, Peier AM, Story GM, Viswanath V (2003) ThermoTRP channels and beyond: mechanisms of temperature sensation. Nat Rev Neurosci 4:529-539.

Peier AM, Moqrich A, Hergarden AC, Reeve AJ, Andersson DA, Story GM, Earley TJ, Dragoni I, McIntyre P, Bevan S, Patapoutian A (2002a) A TRP channel that senses cold stimuli and menthol. Cell 108:705-715.

Peier AM, Reeve AJ, Andersson DA, Moqrich A, Earley TJ, Hergarden AC, Story GM, Colley S, Hogenesch JB, McIntyre P, Bevan S, Patapoutian A (2002b) A heat-sensitive TRP channel expressed in keratinocytes. Science 296:2046-2049.

Premkumar LS, Ahern GP (2000) Induction of vanilloid receptor channel activity by protein kinase C. Nature 408:985-990.

Premkumar LS, Qi ZH, Van Buren J, Raisinghani M (2004) Enhancement of potency and efficacy of NADA by PKC-mediated phosphorylation of vanilloid receptor. J Neurophysiol 91:1442-1449.

Ross RA (2003) Anandamide and vanilloid TRPV1 receptors. Br J Pharmacol 140:790-801.

Schaefer M, Plant TD, Obukhov AG, Hofmann T, Gudermann T, Schultz G (2000) Receptor-mediated regulation of the nonselective cation channels TRPC4 and TRPC5. J Biol Chem 275:17517-17526.

Shin JS, Wang MH, Hwang SW, Cho H, Cho SY, Kwon MJ, Lee SY, Oh U (2001) Differences in sensitivity of vanilloid receptor 1 transfected to human embryonic kidney cells and capsaicin-activated channels in cultured rat dorsal root ganglion neurons to capsaicin receptor agonists. Neurosci Lett 299:135-139.

Smith GD, Gunthorpe MJ, Kelsell RE, Hayes PD, Reilly P, Facer P, Wright JE, Jerman JC, Walhin JP, Ooi L, Egerton J, Charles KJ, Smart D, Randall AD, Anand P, Davis JB (2002) TRPV3 is a temperature-sensitive vanilloid receptor-like protein. Nature 418:186-190.

Story GM, Peier AM, Reeve AJ, Eid SR, Mosbacher J, Hricik TR, Earley TJ, Hergarden AC, Andersson DA, Hwang SW, McIntyre P, Jegla T, Bevan S, Patapoutian A (2003) ANKTM1, a TRP-like channel expressed in nociceptive neurons, is activated by cold temperatures. Cell 112:819-829.

Szolcsanyi J (2004) Forty years in capsaicin research for sensory pharmacology and physiology. Neuropeptides 38:377-384.

Tominaga M, Caterina MJ, Malmberg AB, Rosen TA, Gilbert H, Skinner K, Raumann BE, Basbaum AI, Julius D (1998) The cloned capsaicin receptor integrates multiple pain-producing stimuli. Neuron 21:531-543.

Vellani V, Mapplebeck S, Moriondo A, Davis JB, McNaughton PA (2001) Protein kinase $\mathrm{C}$ activation potentiates gating of the vanilloid receptor VR1 by capsaicin, protons, heat and anandamide. J Physiol (Lond) 534:813-825.

Voets T, Prenen J, Vriens J, Watanabe H, Janssens A, Wissenbach U, Bodding M, Droogmans G, Nilius B (2002) Molecular determinants of permeation through the cation channel TRPV4. J Biol Chem 277:33704-33710.

Voets T, Droogmans G, Wissenbach U, Janssens A, Flockerzi V, Nilius B (2004) The principle of temperature-dependent gating in cold- and heatsensitive TRP channels. Nature 430:748-754.

Wang H, Woolf CJ (2005) Pain TRPs. Neuron 46:9-12.

Watanabe H, Davis JB, Smart D, Jerman JC, Smith GD, Hayes P, Vriens J, Cairns W, Wissenbach U, Prenen J, Flockerzi V, Droogmans G, Benham CD, Nilius B (2002) Activation of TRPV4 channels (hVRL-2/mTRP12) by phorbol derivatives. J Biol Chem 277:13569-13577.

Xu H, Ramsey IS, Kotecha SA, Moran MM, Chong JA, Lawson D, Ge P, Lilly J, Silos-Santiago I, Xie Y, DiStefano PS, Curtis R, Clapham DE (2002) TRPV 3 is a calcium-permeable temperature-sensitive cation channel. Nature 418:181-186.

Xu H, Jin J, DeFelice LJ, Andrews NC, Clapham DE (2004) A spontaneous, recurrent mutation in divalent metal transporter- 1 exposes a calcium entry pathway. PLoS Biol 2:E50.

Zygmunt PM, Petersson J, Andersson DA, Chuang H, Sorgard M, Di Marzo V, Julius D, Hogestatt ED (1999) Vanilloid receptors on sensory nerves mediate the vasodilator action of anandamide. Nature 400:452-457. 